\title{
Pig manure treatment with housefly (Musca domestica) rearing - an environmental life cycle assessment
}

\author{
M. Roffeis ${ }^{1^{*}}$, B. Muys ${ }^{1 *}$, J. Almeida ${ }^{1}$, E. Mathijs ${ }^{1}$, W.M.J. Achten ${ }^{2}$, B. Pastor ${ }^{3}$, Y. Velásquez ${ }^{3}$, A.I. Martinez-Sanchez ${ }^{4}$ \\ and S. Rojo ${ }^{4}$ \\ ${ }^{1}$ KU Leuven, Department of Earth and Environmental Sciences, Division of Forest, Nature and Landscape, P.O. Box 2411, 3001 \\ Leuven, Belgium; ${ }^{2}$ Université libre de Bruxelles, Institute for Environmental Management and Land-use Planning, Avenue \\ Antoine Depage 13, 1050 Brussels, Belgium; ${ }^{3}$ Bioflytech SL, Alicante Science Park, University of Alicante, P.O. Box 99,03080 \\ Alicante, Spain; ${ }^{4}$ Research Institute of Biodiversity - CIBIO, Department of Environmental Sciences and Natural Resources, \\ University of Alicante, P.O. Box 99, 03080 Alicante, Spain; martin.roffeis@ees.kuleuven.be; bart.muys@ees.kuleuven.be
}

Received: 8 September 2014 / Accepted: 6 June 2015

(c) 2015 Wageningen Academic Publishers

\section{RESEARCH ARTICLE}

\begin{abstract}
The largest portion of a product's environmental impacts and costs of manufacturing and use results from decisions taken in the conceptual design phase long before its market entry. To foster sustainable production patterns, applying life cycle assessment in the early product development stage is gaining importance. Following recent scientific studies on using dipteran fly species for waste management, this paper presents an assessment of two insect-based manure treatment systems. Considering the necessity of manure treatment in regions with concentrated animal operations, reducing excess manure volumes with the means of insects presents a potentially convenient method to combine waste reduction and nutrient recovery. An analytical comparison of rearing houseflies on fresh and pretreated pig manure is reported with reference to agricultural land occupation, water and fossil depletion potential. Based on ex-ante modelled industrial scale rearing systems, the driving factors of performance and environmentally sensitive aspects of the rearing process have been assessed. Expressed per kg manure dry matter reduction, the estimated agricultural land occupation varied between 1.4 and $2.7 \mathrm{~m}^{2} \mathrm{yr}$, fossil depletion potential ranged from 1.9 to $3.4 \mathrm{~kg}_{\text {oil eq }}$ and the obtained water depletion potential was calculated from 36.4 to $65.6 \mathrm{~m}^{3}$. System improvement potential was identified for heating related energy usage and water consumption. The geographical context and the utility of the co-products, i.e. residue substrates and insect products, were determined as influential variables to the application potential of this novel manure treatment concept. The results of this study, applied at the earliest stages of the design of the process, assist evaluation of the feasibility of such a system and provide guidance for future research and development activities.
\end{abstract}

Keywords: life cycle design, insect rearing, pig production, recycling, sustainability

\section{Introduction}

The next few decades pose major challenges to the global feed and food sector. By the year 2050 the global human population is expected to increase up to 9.2 billion and, if emerging markets retain their pronounced economic growth, the world's average per capita real income is predicted to rise by a factor 2.4 (Godfray et al., 2010). This will boost the global food demand by $70-100 \%$, and is most likely to accentuate the ongoing dietary shifts favouring higher proportions of meat and fish (Godfray et al., 2010; Tilman et al., 2002). The significance of the effects of agricultural activities on climate change and environmental degradation, such as terrestrial and marine acidification, is well acknowledged and has been demonstrated by many studies (Godfray et al., 2010; Lal, 2013; Parry et al., 2007; Tilman et al., 2002). Feed production (fossil fuel combustion, land use and land use change) and animal husbandry, especially enteric $\mathrm{CH}_{4}$ emissions and $\mathrm{CH}_{4}, \mathrm{~N}_{2} \mathrm{O}$ and $\mathrm{NH}_{3}$ emission as a cause of applied manure management, 
are reported to be most important contributors to the environmental impacts (Lesschen et al., 2011; Nijdam et al., 2012; Petersen et al., 2007; Sandars et al., 2003).

Considerable room for improvement has been estimated for applied manure management and the use of fossil resources in adjacent feed production systems (Steinfield et al., 2006). Conventional manure treatment measures, such as field application, can be detrimental to the hosting environment, particularly in regions with high densities of concentrated animal operation (CAO). Diverting manure to adjacent cropping and grassland systems and applying it excessively relative to plant requirements impairs the quality of connected water bodies and surrounding habitats (Petersen et al., 2007; Sandars et al., 2003; Tilman et al., 2002; Tscharntke et al., 2012). To meet present directives and regulations, farm operations are forced to take alternative disposal options (Lebuf et al., 2013; Petersen et al., 2007; Smet et al., 2003), but existing recycling or nutrient recovery techniques such as anaerobic digestion are either very costly or limited in terms of their volume reduction potential (Dawson and Hilton, 2011; Petersen et al., 2007; Sandars et al., 2003). In search for more efficient and economically viable recycling methods of livestockborne waste streams, latest thinking intends to reduce manure by means of insect rearing. Reared on low value waste streams, different dipteran fly species could not only facilitate significant reductions in waste volumes, but also extract highly valuable proteins, which show considerable potential to be used in feeding regimes of monogastric livestock and carnivorous fish species (Miller et al., 1974; Sheppard, 1983). In addition, residual substrates, still containing $40-60 \%$ of key elements (N, P, K, C), promise further added value in subsequent process stages (e.g. fertiliser, soil remediation material, substrate in anaerobic digestion) (Newton et al., 2005).

Although the potential utility of this idea has been attracting a lot of attention from the scientific, policy and public world (Rumpold and Schlüter, 2013; Van Huis et al., 2014), the actual environmental impact and socioeconomic performance of its implementation remain widely unexplored (Oonincx and De Boer, 2012; Rumpold and Schlüter, 2013; Van Huis et al., 2014).

In order to have an insight in the driving factors of manure degradation performance and environmental impact of insect-based manure treatment, we teamed up environmental scientists with insect experts that conducted experimental trials in an pilot-scale insectbased manure treatment system. Using observations and data on fundamental biophysical in- and output relations as foreground data, we ex-ante modelled two production scenarios, differing in processed manure types and thus technological setups and process organisation. To analyse and compare the environmental impacts of the modelled systems, we conducted a comprehensive environmental life cycle assessment (LCA). The overarching objective was to inform on suitable manure characteristics and identify disproportionate areas of impact in the production systems and delineate optimisation pathways for a sustainable inclusion of insects in current livestock production cycles.

\section{Materials and methods}

\section{Methodology}

An environmental LCA aims at accounting the environmental implications of the whole supply-chain of goods and services throughout their entire life cycle, i.e. from 'cradle to grave'. By focusing on all bio-physical input and output flows that result from creating, using and disposing of a product, LCA studies support a broader perspective on how product systems interact with their accommodating environment. This enables the identification of product scenarios that are less environmental burdensome and assists to counter environmental impacts shifting through the value chain. It also provides opportunity to evaluate and compare input-efficiencies and identify production steps with the highest improvement potential. This latter feature of LCA is particularly useful in product development solutions that opt to adjust production and provision patterns of goods and services towards sustainable principles.

LCA methods have become a broadly applied tool for impact evaluation in the industry, and are nowadays frequently used in engineering and optimisation processes of bio-based product systems (Pawelzik et al., 2013; Swarr et al., 2011).

Generally, LCA practitioners distinguish between two types of LCA approaches: attributional and consequential. Rather than looking at environmental consequences of an analysed decision (consequential LCA), our research focus was placed on environmentally relevant physical flows and the environmental properties. We thus choose the attributional approach, as it corresponds best with the study objectives. The LCA on manure treatment by insect rearing was conducted in accordance to ISO 14040/14044 standards (ISO, 2006a,b) and recent guidelines on life cycle design (Basbagill et al., 2013).

\section{Goal and scope}

The goal of the present study is two-fold. The first objective is to estimate the sustainability and utility potential of state-of-the-art insect rearing techniques, applied in the realm of manure management. In particular, we aim at a better understanding of the production systems and their performance driving features. Secondly, taking an engineering perspective, we tested and compared two 
manure types, different in their bio-physical properties, to assess the substrate suitability and identify production steps with the highest improvement potential in treatment efficiency and environmental sustainability. The analytical results provide recommendations for practitioners, future research and development activities. The surveyed systems were designed to facilitate reduction of pig manure mass and water content from large-scale pig fattening units. Since the utility potential and thus economic value of coproducts, i.e. insect product and residue substrate, has not been clarified, any conclusions on the nature of a possibly existing allocation problem remain highly hypothetical. Hence we have applied a conservative approach, burdening all estimated environmental impacts to the studied function, i.e. the service of manure reduction. As such the overall impact does not get diluted over different products of which the functions are either unclear or inexistent. An allocation of environmental impacts between service performance and co-products by other means than economic value, i.e. applying mass or energy ratios, was considered unreasonable, if not scientifically unjustifiable. As it reflects best the function of manure degradation, we used the reduction of $1 \mathrm{~kg}$ manure dry matter (DM) as functional unit.

Since we opted for a comparison between the process performances of different manure types in insect-based manure treatment systems and did not attempt to make any comparisons with product systems other than the ones surveyed, we did not outline our system models against other life cycles of manure treatment. The determining factor for the definition of the system boundaries was the data availability. Starting with the unit process and material flow closest to the final output (service of manure treatment) we followed all related material flows further upstream until first hand data became unavailable. This iterative 'bottom-up approach' resulted in a life cycle inventory (LCI) comprising the collection and assembly of raw materials, the manure degradation and larvae separation and the finishing of the final co-product (e.g. drying and packaging of separated insect pupae). Due to limited data availability the assessed LCIs do not include the use and disposal phase of the final process outputs (insect product and residue substrate) as well as the dewatering process, located upstream to the processing of the pre-treated manure. Since extra assumptions and estimation were expected to add more noise to the model than information, the presented LCA thus only estimates the environmental impacts for a very confined process flow, i.e. from the procurement of material and resources to the separation of the final product outputs. The system borders are mapped in the flow diagrams of Figure 1 and 2 .

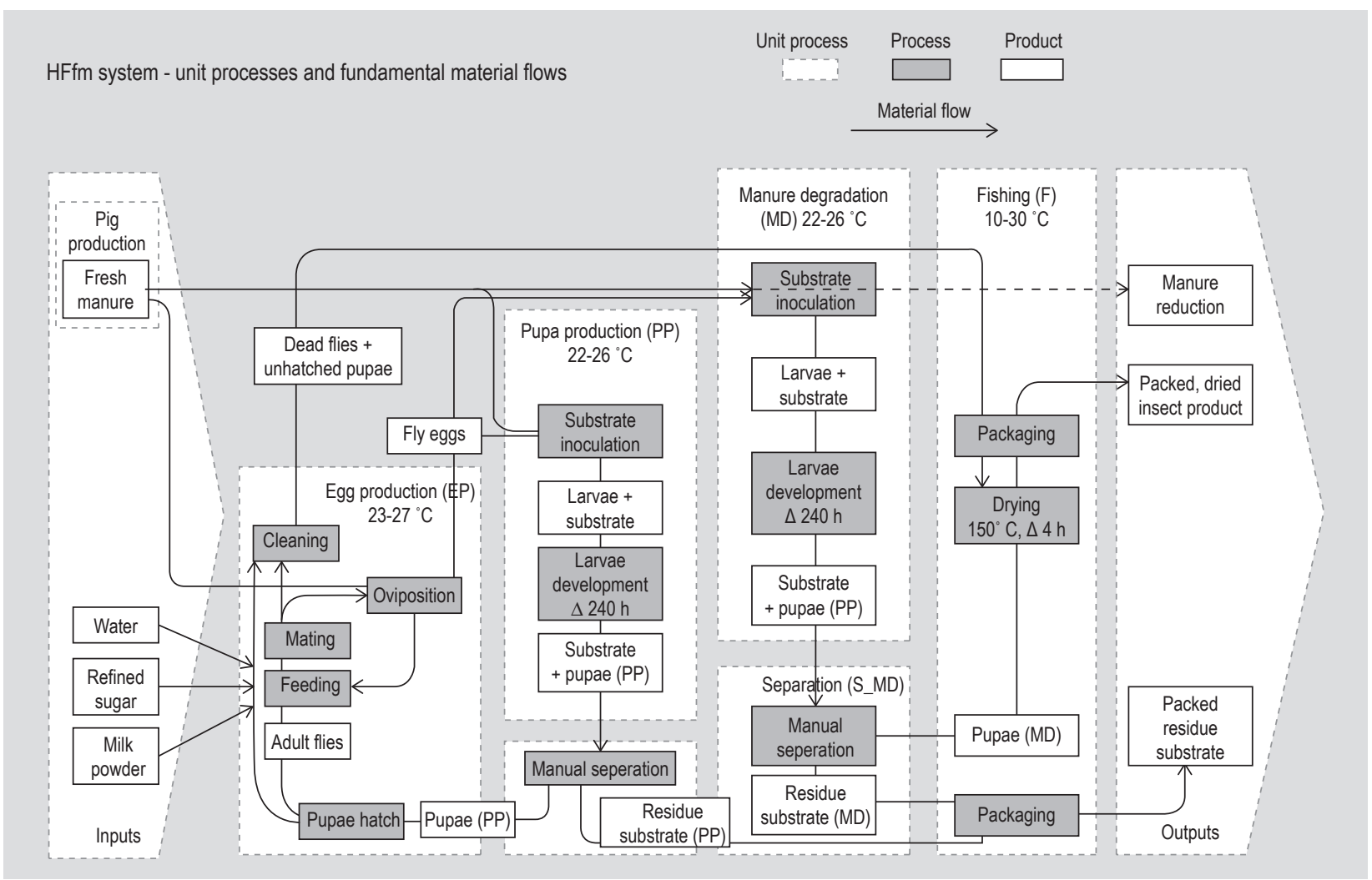

Figure 1. Schematic flow chart of rearing housefly (Musca domestica) on fresh pig manure within chosen system boundaries. Biophysical in- and outputs, unit processes and fundamental material flows. 


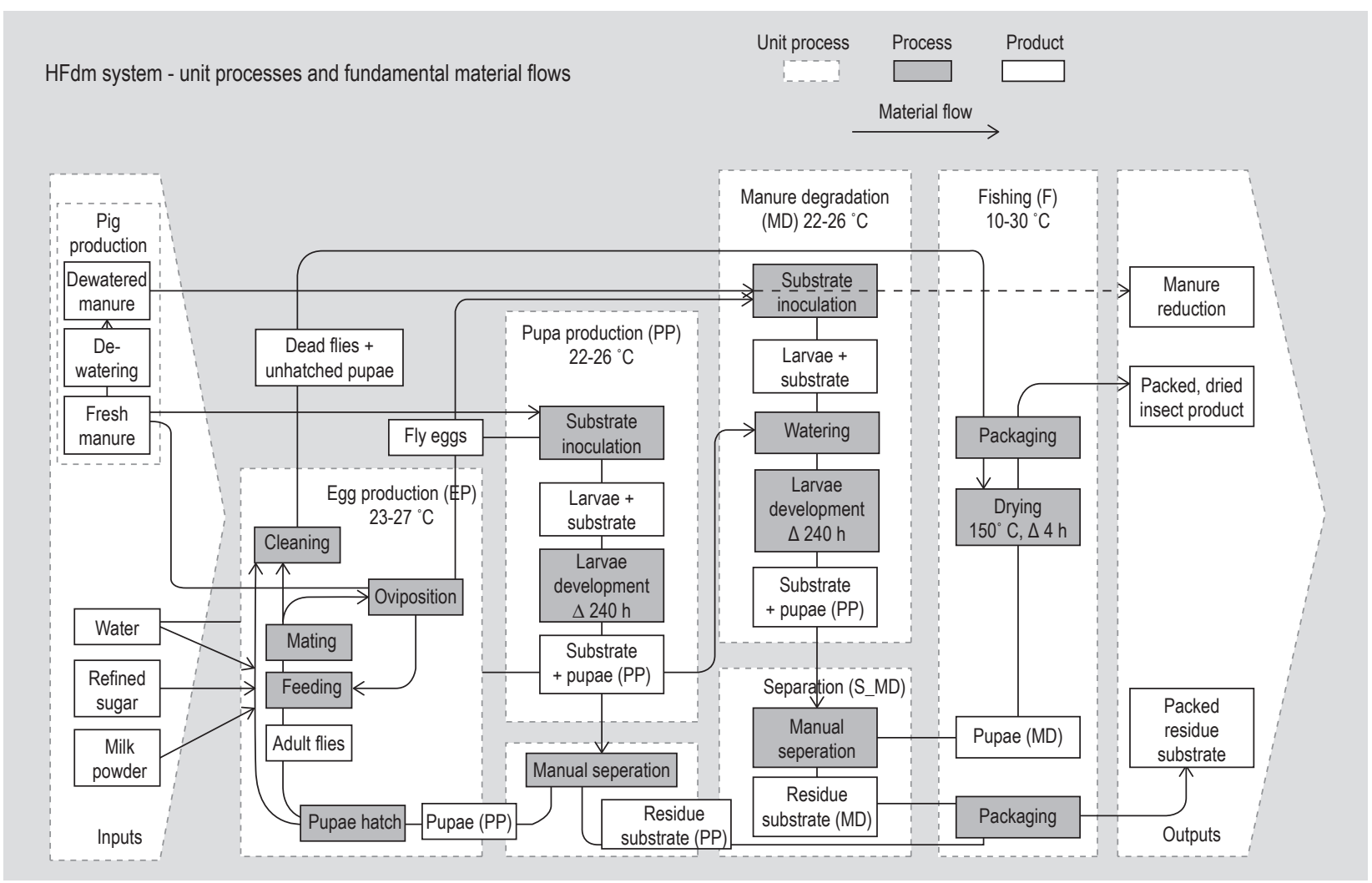

Figure 2. Schematic flow chart of rearing housefly (Musca domestica) on dewatered pig manure within chosen system boundaries. Biophysical in- and outputs, unit processes and fundamental material flows.

\section{Impact assessment}

The environmental impacts were calculated using the ReCiPe method. This method entails 18 impact categories addressed at the midpoint level, and three final damage categories (human health, ecosystem diversity and resource availability), assessed at end point level (Goedkoop et al., 2008). As data on direct emissions were not available, the results for related impact categories, such as climate change potential or terrestrial acidification, has been audited not representative. As a consequence, emission related impact categories as well as aggregated final damage categories were not taken into consideration. The results are presented for a selection of midpoint impact categories most suitable to indicate the resource efficiency (Table 1).
The environmental impacts were calculated with LCA software SimaPro ${ }^{\circledR}$ (PRé, Amersfoort, the Netherlands).

\section{Life cycle inventory}

Our production models largely, but not completely, draw on experimental trials conducted by researchers of the Research Institute of Biodiversity (CIBIO), University of Alicante (Alicante, Spain) and the Institute of Zoology, Slovak Academy of Sciences (Bratislava, Slovakia). With the objective to give recommendations for the operation of industrial-scale biodegradation facilities, aforementioned research groups performed experimental trials with houseflies (Musca domestica) in two different established pilot-scale production system, one in Slovakia and the other

Table 1. Selection of environmental impact categories at midpoint level (ReCiPe method). Abbreviations, characterisation factor name and units.

$\begin{array}{llll}\text { Impact category name } & \text { Abbreviation } & \text { Characterisation factor name } & \text { Unit } \\ \text { agricultural land occupation } & \text { ALO } & \text { agricultural land occupation potential } & \mathrm{m}^{2} \mathrm{yr}_{\text {agricultural land }} \\ \text { water depletion } & \text { WD } & \text { water depletion potential } & \mathrm{m}^{3} \\ \text { fossil resource depletion } & \text { FD } & \text { fossil depletion potential } & \mathrm{kg}_{\text {oil eq }}\end{array}$


in Spain. The models analysed in this study are based on the data obtained from the biodegradation plant located in Alpuente (Valencia, Spain). The rearing trials aimed to assess the biodegradation performance of selected laboratory strains of $M$. domestica under varying production conditions. Apart from varied climatic settings and manure characteristics, different production techniques and process intensities have been tested. The research findings provide a detailed description on optimal production conditions and process organisation, comprising particulars, such as optimal larval stocking densities, husbandry of adults and egg harvesting techniques (Čičková et al., 2012a,b, 2013; Pastor et al., 2011, 2014).

The published experimental results, however, did not provide complete information on technological equipment and organisation of workflows in an industrial-scale production facility. To overcome this limitation we consulted specialists at CIBIO, University of Alicante, to formulate the design of an up-scaled, industrial production capable to process $1000 \mathrm{~kg}$ of manure per week. Within the framework of a scientific collaboration, we jointly modelled the construction of buildings, heat and energy consumption, logistics, electronic devices, work flows and labour expenditure necessary to facilitate optimal production flows in two up-scaled production scenarios based on data from the system developed in Spain (Čičková et al., 2012b). The basic production functions, defining applicable input-output relations, were built after conversion factors observed in aforementioned rearing trials. To ensure representativeness and correct for seasonal variations, the production functions were parameterised with annual averages. Making resource of the on-hand experience of the researchers at $\mathrm{CIBIO}$, we further applied safety margins that account for regular production outtakes to be expected. The insect-steered manure treatment models were conceived as an integrated unit of a large-scale pig production operation in southern Spain. The production function was thus parameterised with site-characteristic data, i.e. climate data, water supplying sources, energy mix and proximity to providing markets, applicable for the greater Alicante area.

To mimic a regional context with a high density of CAOs, i.e. produced manure volumes largely exceed plant requirements in adjacent crop production systems, we considered the treated manure types as a true waste stream, which denotes a non-tradable good, free of economic costs and thus free of environmental load from its upstream product system (economic allocation) (Guinée et al., 2004; Pawelzik et al., 2013).

To obtain inventory data on material composition, energy demand, lifespan and environmental impact of process involved electronic devices we have used various sources, including publications on material composition of e-wastes from electrical and electronic equipment and product data sheets from manufacturers (EMPA, 2014; Freegard and Claes, 2009). Due to lack of data, we did not account for possible direct emissions that occur during the rearing process.

Necessary background data on all material and energy flows was extracted from EcoInvent 3.0 (Swiss Centre for Life Cycle Inventories, Dübendorf, Switzerland) and the German agricultural data collection KTBL (Döhler, 2009).

\section{Scenarios}

Two different production scenarios were modelled. The first system (housefly reared on fresh pig manure, henceforth named HFfm) was designed to degrade fresh pig manure with an average water content of $82.9 \%$. The second system (housefly reared on dewatered pig manure, henceforth named HFdm) processed pre-treated pig manure with a reduced water content of $76.3 \%$ (Table 2 and 3 ). The pre-treatment or dewatering of the manure is a common practice in Spanish farms. The pre-treatment consists in a solid-liquid separation with a decanter centrifuge of the pig slurry. The liquid fraction is usually used in farms as irrigation water for crops, but the solid fraction has not any application yet (Čičková et al., 2012b). Most of the manure waste produced in intensive farms is the pre-treated manure, thus, the possibility of digesting the solid fraction by fly larvae was also studied.

As illustrated in Figure 1 and 2, the production processes in both systems are organised in 6 unit processes. Pupa production (PP), pupa separation (S_PP) and 31.3\% of the output from the egg production unit (EP) are part of an internal production loop with the sole purpose of maintaining the adult colony. The interaction of the remaining output of the EP unit (68.7\%), the manure degradation (MD) unit and related separation (S_MD) and finishing (F) unit contribute to the determinant or external outputs of the production systems, i.e. service of manure degradation, dried pupae and residue substrates (Figure 1 and 2).

The aforementioned experimental studies conclude that the limiting factor in housefly driven manure biodegradation is the availability of eggs (Čičková et al., 2012b; Pastor et al., 2011). As a starting point for both production models we assumed a sequenced maintenance of 80 adult colonies that were kept in separate rearing cages $\left(0.84 \mathrm{~m}^{3}\right)$, stocked with 34,000 individuals each (40,000 pupas). A continuous egg production is facilitated due to an evenly phased setup of 80 adult cages, organised in 10 groups of 8 synchronised adult cages. The production cycle of each cage takes 22 days and starts with the pupa introduction (Table 2). After a maturing phase of 7 days, the flies are provided with oviposition substrate (fresh pig manure) on a daily basis for a period of 14 days. Following the results from the 
Table 2. Model setup of the egg production and manure degradation unit in the manure treatment systems with houseflies reared on fresh pig manure (HFfm) and on dewatered pig manure (HFdm). Unifying and distinguishing process parameters.

\begin{tabular}{|c|c|c|c|c|}
\hline \multirow[t]{2}{*}{ Unit processes/process parameters } & \multirow[t]{2}{*}{ Unit } & \multicolumn{2}{|c|}{ Amount } & \multirow[t]{2}{*}{ Data sources (foreground data | background data) } \\
\hline & & HFfm & HFdm & \\
\hline \multicolumn{5}{|l|}{ Egg production } \\
\hline Adult colonies ${ }^{1}\left(0.84 \mathrm{~m}^{3}\right)$ & p & \multicolumn{2}{|c|}{80} & Modelled | Čičková et al., 2012b; Pastor et al., personal communication \\
\hline Pupae per colonies & $\mathrm{p}$ & \multicolumn{2}{|c|}{40,000} & Modelled | Čičková et al., 2012b; Pastor et al., personal communication \\
\hline Duration of one adult colony cycle & $d$ & \multicolumn{2}{|c|}{22} & Modelled | Čičková et al., 2012b; Pastor et al., personal communication \\
\hline Total egg production per day & $\mathrm{kg}$ & \multicolumn{2}{|c|}{0.1293} & Modelled | Čičková et al., 2012b; Pastor et al., personal communication \\
\hline Eggs for adult colony maintenance & $\mathrm{kg}$ & \multicolumn{2}{|c|}{0.0405} & Modelled | Čičková et al., 2012b; Pastor et al., personal communication \\
\hline Eggs for manure treatment & $\mathrm{kg}$ & \multicolumn{2}{|c|}{0.0888} & Modelled | Čičková et al., 2012b; Pastor et al., personal communication \\
\hline $\begin{array}{l}\text { Larvae density for pupa reproduction (kg } \\
\text { eggs/kg manure) }\end{array}$ & $\mathrm{kg}$ & \multicolumn{2}{|c|}{0.0005} & Modelled | Čičková et al., 2012b; Pastor et al., personal communication \\
\hline \multicolumn{5}{|l|}{ Manure degradation } \\
\hline $\begin{array}{l}\text { Larvae density for manure treatment (kg } \\
\text { eggs/kg manure) }\end{array}$ & $\mathrm{kg}$ & 0.0008 & 0.0005 & Modelled | Čičková et al., 2012b; Pastor et al., personal communication \\
\hline $\mathrm{DM}^{2}$ content of processed manure types & $\%$ & 17.1 & 23.7 & Modelled | Čičková et al., 2012b; Pastor et al., personal communication \\
\hline Duration of degradation & $d$ & \multicolumn{2}{|c|}{10} & Modelled | Čičková et al., 2012b; Pastor et al., personal communication) \\
\hline Degradation (kg manure $\mathrm{FM}^{2} /$ day) & $\mathrm{kg}$ & 108.0 & 167.4 & Modelled | Čičková et al., 2012b; Pastor et al., personal communication \\
\hline DM content of the residue substrates & $\%$ & 49.6 & 59.1 & Modelled | Čičková et al., 2012b; Pastor et al., personal communication \\
\hline
\end{tabular}

originating experimental trials, we calculated an average egg yield of $35.6 \mathrm{~g}$ fly eggs per adult cage and production cycle (Supplementary Table S1). The EP cycle stops with the killing of the remaining adults and the cleaning of the accommodating cages (Čičková et al., 2012b; Pastor et al., personal communication).

The modelled setup facilitates an average egg output of $0.129 \mathrm{~kg}$ fly eggs per day. Due to this unifying parameter the
EP unit and the joint unit processes, PP and S_PP, coincide in both production scenarios (Table 2).

A continuous supply of vital adults, requires fast hatching of pupae with a high individual weight. Such pupae, suitable for reproduction purposes, are most effectively obtained by rearing larvae on a relatively low stocking density of $0.5 \mathrm{~g}$ fly eggs per kg fresh manure (Čičková et al., 2012b). To ensure continuous pupa supply we have modelled the PP unit in

Table 3. Relevant biophysical inputs and outputs calculated per kg manure DM reduction. Comparison between the manure treatment models with houseflies reared on fresh pig manure (HFfm) and on dewatered pig manure (HFdm). Production models are optimised within the limits of a daily fly egg production of $0.129 \mathrm{~kg}$ (Airwell, 2014; Čičková et al., 2012b; CR, 2014; Davis et al., 1992; Döhler, 2009; Reckmann et al., 2013; Rubag, 2014; Texene, 2014).

\begin{tabular}{|c|c|c|c|c|}
\hline \multirow[t]{2}{*}{ Input/output } & \multirow[t]{2}{*}{ Unit } & \multicolumn{2}{|c|}{ Amount } & \multirow[t]{2}{*}{ Data sources (foreground data | background data) } \\
\hline & & HFfm & HFdm & \\
\hline Water & I & 16.0 & 30.6 & Modelled \\
\hline Production flow & I & 1.3 & 3.0 & Čičková et al., 2012b; Pastor et al., personal communication) | Ecoinvent 3.0 \\
\hline Cleaning & 1 & 14.7 & 27.6 & Čičková et al., 2012b; Pastor et al., personal communication | Ecoinvent 3.0 \\
\hline Space & $m^{2}$ & 0.0020 & 0.0040 & Modelled \\
\hline Production facility ${ }^{1}$ & $m^{2}$ & 0.0020 & 0.0039 & Čičková et al., 2012b; Pastor et al., personal communication | Ecoinvent 3.0 \\
\hline Storage container ${ }^{2}$ & $m^{2}$ & 0.0001 & 0.0001 & Assumption ${ }^{6}$ | Rubag, 2014; Ecoinvent 3.0 \\
\hline
\end{tabular}


Table 3. Continued.

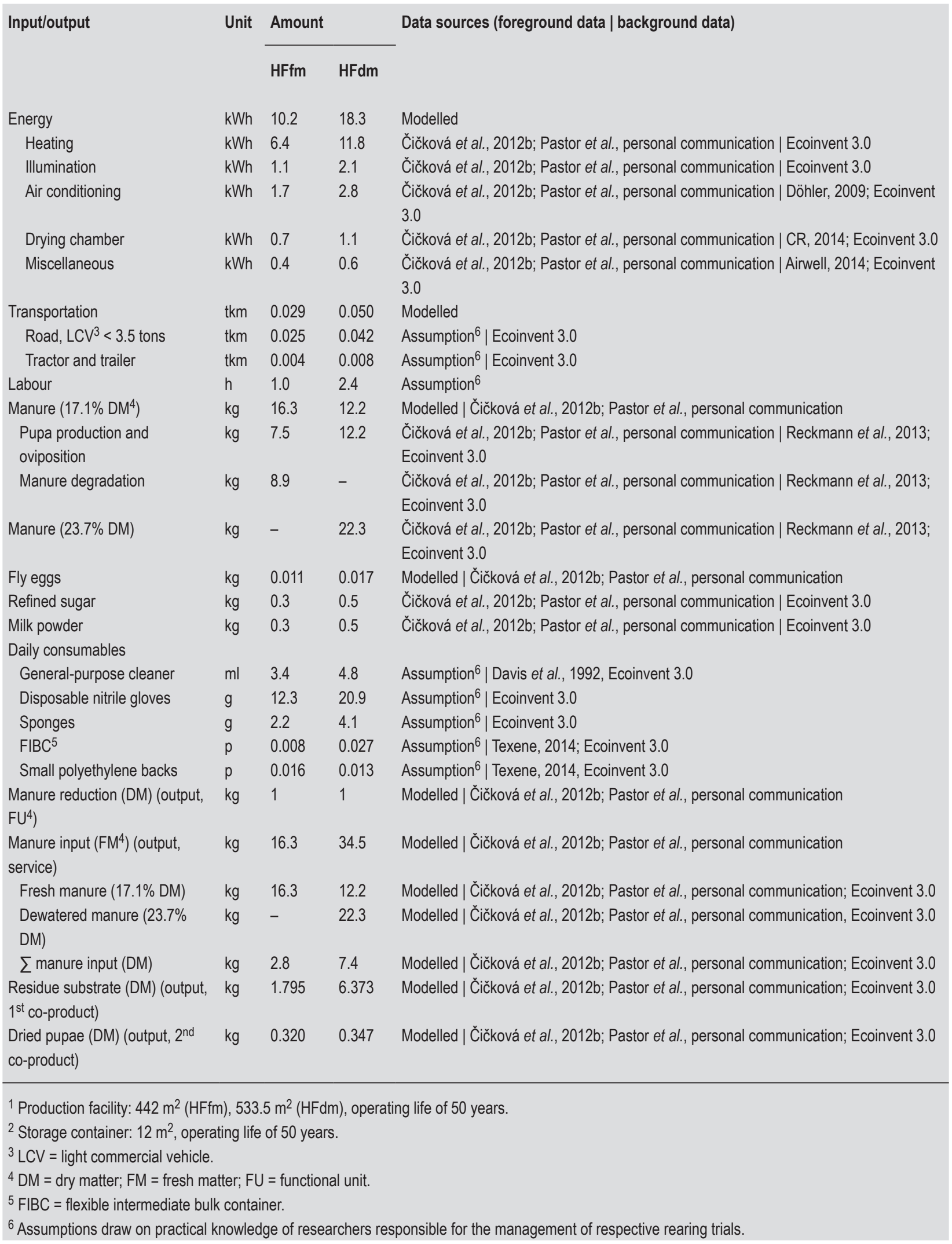


an evenly phased setup of 270 rearing trays, organised in 10 groups with 27 rearing trays each. The pupa production takes 10 days and starts with the inoculation of the fresh pig manure. At the $10^{\text {th }}$ day the pupation is completed and the pupae are separated from the residue substrate by manually sifting the substrate-pupa-mixture (Table 2 and Supplementary Table S2). Figure 1 and 2 illustrate how this internal reproduction loop feeds into the egg production unit in order to keep the adult colony at a constant number.

As the pupa production forms a dependent variable of the egg production function, the sequenced setups of the PP batches as well as the 80 adult colonies have been synchronised to facilitate a continuous and manageable workload (Supplementary Table S1 and S2). To translate the experimental results into a realistic production scenario, we considered regular production outtakes. Given the high variability of egg and pupa yields observed in the originating experimental trials, we accounted for an average production loss of $10 \%$ (Pastor et al., personal communication). As a result, to facilitate a continuous reproduction of $2.21 \mathrm{~kg}$ (145,454 pupae) pupa per day, a total of $40.5 \mathrm{~g}$ fly eggs per day were calculated necessary which eventually consumed $31 \%$ of the daily average egg output (129.3 g fly eggs per day). After deduction of eggs consumed in the reproduction loop, a total of $88.8 \mathrm{~g}$ per day were left to 'fuel' the manure treatment (Table 2 and Supplementary Table S1 and S2).

The different manure properties in the HFfm and HFdm system affected the specific biodegradation performance, in- and output variables and thus process organisation. To achieve a fast and complete biodegradation of the fresh pig manure, the experimental results suggest to apply larval densities relatively higher ( $0.8 \mathrm{~g}$ per $\mathrm{kg}$ fresh manure) to the one used for pupa reproduction $(0.5 \mathrm{~g}$ per $\mathrm{kg}$ fresh manure) (Table 2 and Supplementary Table S2 and S3). When corrected for possible production losses $(-2.7 \%)$, the remaining $88.8 \mathrm{~g}$ of fly eggs allowed to setup and separate 36 manure degradation batches of $3 \mathrm{~kg}$ fresh manure each (108.0 kg/day) (Supplementary Table S3). Different from fresh pig manure, degrading dewatered pig manure has proven most effective with larval densities equal to the one used for pupa reproduction ( $0.5 \mathrm{~g}$ per $\mathrm{kg}$ fresh manure). This difference in the egg densities applied to the manure are based on previous results (Čičková et al., 2012b). The densities applied to the dewatered manure were lower to avoid larval competition, as the nutritive content in this kind of manure is lower due to the process of solid-liquid separation suffered. The disposable amount of $88.8 \mathrm{~g}$ fly eggs allowed setting up 55.8 batches of $3 \mathrm{~kg}$ each $(167.4$ kg/day) (Table 2 and Supplementary Table S4). Similar to the PP unit process, we accounted 10 days to have the manure fully degraded and larvae pupated. Subsequently, the substrate-pupa-mixture was foreseen to be separated by manual sifting. In accordance with aforementioned experimental findings, the residual water content of the residue substrates was assumed to be $50.38 \%$ in the $\mathrm{HFfm}$ system and $40.9 \%$ in the HFdm system. The production scenarios propose the separated pupae to be dried for 4 $\mathrm{h}$ at $105^{\circ} \mathrm{C}$ using a drying chamber. Furthermore, dried pupae were foreseen to be packed and temporarily stored. Although the remaining water contents of the residue substrates are relatively high, we assumed the packaging of the residue substrates from the PP and MD unit to improve transportability. To prevent the spoiling of the residue substrates, we calculated with an average storage time of $12 \mathrm{~h}$. Established by the Spanish authorities for fertilisers (Real Decreto 506/2013; Agencia Estatal Boletín Oficial del Estado 2013), the residue substrate obtained after degradation should be further dried to below a water content of $40 \%$, in order to be commercialised. However, because of data gaps we were not able to account for such a subsequent processing.

Since the Mediterranean climate in southern Spain provides favourable temperatures for insect rearing from April till October, we assumed additional heating efforts for six months per year. To keep the temperature regime of the high optimal observed in aforementioned rearing trials, we followed the setup of the rearing trials and assumed the process accommodating rooms to be heated by electrical powered oil radiators. As air temperatures above $28{ }^{\circ} \mathrm{C}$ have proven to inhibit the bioconversion performance of the fly larvae, we have calculated for additional electrical energy consumption for air conditioning (cooling) measures from June until September (Pastor et al., personal communication). The required air humidity was assumed to be achieved by evaporation from water carrying vessels and moist manure (Pastor et al., personal communication).

\section{Sensitivity analyses}

To test the robustness of our production scenarios, we conducted sensitivity analyses. By solely varying variables of interest and keeping all other inputs constant, sensitivity analyses reveals the influence of tested variables on the overall results.

The assumptions employed for stationary equipment (e.g. electronic devices, rearing cages, etc.), daily consumables (e.g. disposable nitrile gloves, general-purpose cleaner, etc.) and construction of the production facilities (properties and amount of construction materials, etc.), are inevitably associated with uncertainties. To analyse how these assumptions affected the overall environmental impact of our production models, we conducted a sensitivity analysis by deleting all assumed technological inputs. Hereafter, we reran the life cycle impact assessments (LCIA) and compared the results with the ones of the complete scenarios. 


\section{Results}

\section{Life cycle inventory analysis}

The analysis of the manure treatment performance revealed pronounced differences in the bioconversion rate between both systems. Though the separated insect biomass $\left(2^{\text {nd }}\right.$ coproduct) per kg manure DM reduction was found similar in both systems (HFfm: $0.320 \mathrm{~kg}$ dried pupa (HFfm) and 0.347 $\mathrm{kg}$ dried pupa (HFdm)), the associated manure throughput differed substantially (Figure 3 and Table 3 ). To facilitate the reduction of $1 \mathrm{~kg}$ manure DM, the modelled HFfm system needed to process $7.4 \mathrm{~kg}$ manure DM $(34.5 \mathrm{~kg}$ manure fresh matter). With a throughput of only $2.8 \mathrm{~kg}$ manure DM (16.3 $\mathrm{kg}$ manure fresh matter) the HFfm system achieved the same level of manure reduction (Table 3 ). As a cause-effect the lower bioconversion rate in the HFdm system resulted in a higher output of residue substrates $\left(1^{\text {st }}\right.$ co-product $)$ per $\mathrm{kg}$ manure DM reduction. With $6.4 \mathrm{~kg}$ residue substrate DM per $\mathrm{kg}$ manure DM reduction, the HFdm system generated $355 \%$ the amount of residue substrate of the HFfm system (Table 3). The observed differences in bioconversion rates and thus manure reduction become more apparent when plotted, as it has been done in Figure 3.

The observed differences in the bioconversion rate are directly mirrored by input efficiencies of relevant biophysical inputs. Measured against $1 \mathrm{~kg}$ of manure DM reduction, the HFfm model was found to operate on more efficient input/output relations. The reduction of $1 \mathrm{~kg}$ manure DM went along with an average consumption of $16.0 \mathrm{l}$ water, $10.2 \mathrm{kWh}$ electrical energy, 0.029 tonne kilometre (tkm)

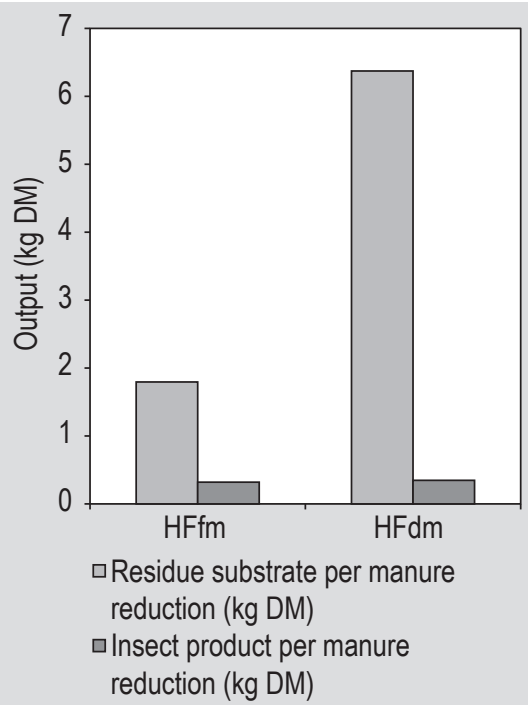

Figure 3. Co-product outputs of the manure treatment models with houseflies reared on fresh pig manure ( $\mathrm{HFfm}$ ) and on dewatered pig manure (HFdm): output of residue substrate (kg dry matter; DM) and insect product (kg DM) per kg manure DM reduction. transportation and $1.0 \mathrm{~h}$ labour. In contrast, the HFdm system required 30.61 water (191\%), $18.3 \mathrm{kWh}$ electrical energy (180\%), $0.050 \mathrm{tkm}$ transportation (171\%) and $2.4 \mathrm{~h}$ labour (234\%) to reduce $1 \mathrm{~kg}$ manure DM (Table 3).

Although the applied larval density and thus egg consumption per $\mathrm{kg}$ manure input was lower in the HFdm system, the lower conversion rate resulted in a comparatively higher fly egg demand per $\mathrm{kg}$ manure reduction (Table 2 and 3). The HFdm system, using $0.017 \mathrm{~kg}$ fly eggs per $1 \mathrm{~kg}$ manure DM reduction, required almost 63\% more fly eggs than the HFfm system $(0.011 \mathrm{~kg}$ fly eggs per kg manure DM reduction).

Since the throughput of manure in both production systems was geared in the limitation of a daily fly egg production of $0.129 \mathrm{~kg}$ eggs, a $40 \%$ lower larval density and thereby upped throughput of manure in the HFdm system translated into comparatively higher input of stationary equipment. As it is shown in Table 4, considerable differences have been calculated for the input of process equipment, devices for climate control and production space. The larger manure throughput in the HFdm system implied a higher number of rearing trays (1,012 p; HFdm and 773 p; HFfm), which in turn required more rearing space $\left(533 \mathrm{~m}^{2}\right.$; HFdm and $\left.442 \mathrm{~m}^{2} ; \mathrm{HFfm}\right)$. As the space defines the scale of necessary heating and air-conditioning measures, the differences between the HFfm and HFdm system are reflected in the input of devices for climate control as well (Table 4).

Though, when measured against manure DM reduction, the input efficiency in the HFdm was found to be comparatively lower to the one of the HFfm system, the higher throughput of manure in the HFdm system, however, went along with substantial water reduction (Table 2 and 3 ). In order to reflect on this feature, Figure 4 illustrates how input efficiencies are subject to the point of reference.

Labour, energy, water and rearing equipment, such as plastic trays, trolleys and claimed production space act as dependent variables that increase their proportional input to the increase of throughput (Table 3). Since the inputs for EP, PP and S_PP coincide in both systems, digression effects become recognisable. Depending on the point of reference, the economy of scale gives advantage to either the HFfm system or the HFdm system. As it has been demonstrated in Table 3, when measured against $\mathrm{kg}$ manure DM reduction, the HFfm system performs more efficiently than the HFdm system. Especially the inputs of labour and water were found substantially lower (Figure 4A). Anyhow, when inputs are referenced to $\mathrm{kg}$ manure DM input the input efficiencies are reversed, although differences between the HFfm and HFdm system appear less accentuated. Measured against kg manure DM input, the HFdm system, facilitating a higher manure throughput from same egg amounts, operates on comparably lower inputs of labour, electricity and water 
Table 4. Stationary equipment employed in the manure treatment models with houseflies reared on fresh pig manure (HFfm) and on dewatered pig manure (HFdm). Production models are optimised within the limits of a daily fly egg production of $0.129 \mathrm{~kg}$ (Airwell, 2014; Čičková et al., 2012b; EMPA, 2014; Freegard and Claes, 2009; Rubag, 2014).

\begin{tabular}{|c|c|c|c|c|c|}
\hline \multirow[t]{2}{*}{ Stationary equipment } & \multirow{2}{*}{$\begin{array}{l}\text { Lifespan } \\
\text { (days) }\end{array}$} & \multirow[t]{2}{*}{ Unit } & \multicolumn{2}{|c|}{ Amount } & \multirow[t]{2}{*}{ Data sources (foreground data | background data) } \\
\hline & & & HFfm & HFdm & \\
\hline \multicolumn{6}{|l|}{ Construction } \\
\hline Production facility ${ }^{1}$ & 18,250 & $m^{2}$ & 442 & 533 & Čičková et al., 2012b; Pastor et al., personal communication | Ecoinvent 3.0 \\
\hline Storage container ${ }^{2}$ & 18,250 & $m^{2}$ & 12 & 12 & Assumption ${ }^{3}$ | Rubag, 2014; Ecoinvent 3.0 \\
\hline \multicolumn{6}{|l|}{ Electronic devises } \\
\hline Drying chamber & 9,125 & $\mathrm{p}$ & 1 & 1 & Assumption $^{3}$ | CR, 2014; Ecoinvent 3.0 \\
\hline Oil radiator & 9,125 & $p$ & 5 & 6 & $\begin{array}{l}\text { Pastor et al., personal communication | EMPA, 2014; Freegard and Claes, 2009, } \\
\text { Ecoinvent } 3.0\end{array}$ \\
\hline Air conditioner & 3,650 & $\mathrm{p}$ & 2 & 2 & $\begin{array}{l}\text { Pastor et al., personal communication |EMPA, 2014; Freegard and Claes, 2009; } \\
\text { Ecoinvent } 3.0\end{array}$ \\
\hline Vacuum cleaner & 3,650 & $p$ & 1 & 1 & $\begin{array}{l}\text { Pastor et al., personal communication | EMPA, 2014; Freegard and Claes, 2009; } \\
\text { Ecoinvent } 3.0\end{array}$ \\
\hline Scale & 3,650 & $\mathrm{p}$ & 1 & 1 & $\begin{array}{l}\text { Pastor et al., personal communication | EMPA, 2014; Freegard and Claes, 2009; } \\
\text { Ecoinvent } 3.0\end{array}$ \\
\hline Data logger & 2,555 & $\mathrm{p}$ & 1 & 1 & Assumption ${ }^{3}$ | EMPA, 2014; Freegard and Claes, 2009; Ecoinvent 3.0 \\
\hline \multicolumn{6}{|l|}{ Process equipment } \\
\hline Adult cages & 9,125 & p & 80 & 80 & Čičková et al., 2012b; Pastor et al., personal communication | Ecoinvent 3.0 \\
\hline Trolleys & 9,125 & $p$ & 35 & 46 & Čičková et al., 2012b; Pastor et al., personal communication | Ecoinvent 3.0 \\
\hline Plastic trays & 3,650 & $p$ & 773 & 1012 & Čičková et al., 2012b; Pastor et al., personal communication | Ecoinvent 3.0 \\
\hline $\begin{array}{l}\text { Tables (chromium } \\
\text { steel) }\end{array}$ & 18,250 & p & 4 & 4 & Čičková et al., 2012b; Pastor et al., personal communication | Ecoinvent 3.0 \\
\hline Racks (iron alloy) & 18,250 & p & 3 & 3 & Čičková et al., 2012b; Pastor et al., personal communication | Ecoinvent 3.0 \\
\hline Oviposition vessels & 730 & $\mathrm{p}$ & 80 & 80 & Čičková et al., 2012b; Pastor et al., personal communication | Ecoinvent 3.0 \\
\hline Sieves & 1,460 & $\mathrm{p}$ & 4 & 4 & Čičková et al., 2012b; Pastor et al., personal communication | Ecoinvent 3.0 \\
\hline \multicolumn{6}{|l|}{ Miscellaneous } \\
\hline Glass & 1,095 & $\mathrm{~kg}$ & 6 & 6 & Assumption $^{3}$ | Ecoinvent 3.0 \\
\hline Chromium steel & 1,095 & $\mathrm{~kg}$ & 6 & 6 & Assumption ${ }^{3}$ | Ecoinvent 3.0 \\
\hline PVC & 1,095 & $\mathrm{~kg}$ & 3 & 3 & Assumption ${ }^{3}$ | Ecoinvent 3.0 \\
\hline
\end{tabular}

(Figure 4B). The relative input of cleaning measures and material inputs (e.g. plastic trays, oil radiators and packaging material) relate in similar fashion as can be gathered from Table 5.

Measuring against $1 \mathrm{~kg}$ manure DM input, provides also a new perspective on the differences in biodegradation between both systems. The HFfm system, yielding $0.114 \mathrm{~kg}$ dried pupa per kg manure DM input, is capable of extracting more than twice as much insect DM than the HFdm system (0.047 kg dried pupa per kg manure DM input) (Table 5).

Regardless the question whether manure DM input or manure DM reduction describes best the service of tested manure treatment models, changing the point of reference is pertinent to elucidate and contextualise the process specific input-output relations. When comparing Table 3 and 5, especially the noticeable water inputs in both systems become particularly apparent. In the geographical context of southern Spain water consumption is an important issue. The largest percentage of water is consumed in cleaning efforts that maintain an adequate level of hygiene. Adjusted cleaning measures were modelled for each unit processes. Cleaning, especially in the highly itemised manure degradation unit, was associated with substantial water input, which is mirrored by the differences in water use between the HFfm and HFdm system (Figure 4A). To reduce $1 \mathrm{~kg}$ of pig manure DM the $\mathrm{HFfm}$ system required 

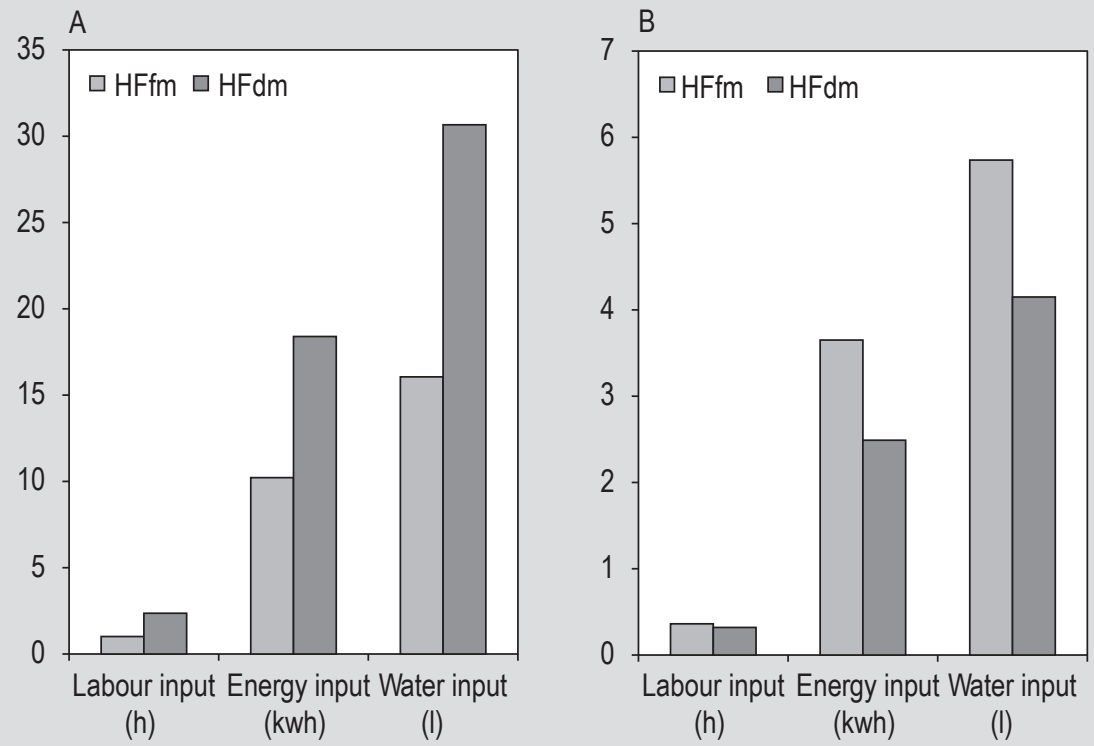

Figure 4. Relevant inputs expressed per (A) $\mathrm{kg}$ manure dry matter reduction and (B) $\mathrm{kg}$ manure dry matter input (HFfm = housefly reared on fresh pig manure; HFdm = housefly reared on dewatered pig manure). Relevant inputs comprise labour (in h), energy (in kWh) and water (in I).

16 1, while the HFdm almost used double that amount (31 1). Subtracting the water needed in the cleaning measures, the HFfm and HFdm system required 1.34 and $3.01 \mathrm{l}$ per $\mathrm{kg}$ manure DM reduction respectively. These comparably small amounts of water are applied in the drinking vessels of the EP unit and in adjusting the substrate moisture of the MD unit of the HFdm system (Table 3 and Figure 4A).

The substantial differences in energy usage between both systems, are largely explained by electrical powered oil radiators and air conditioning devices (Figure 4). Since the HFdm system claims more rearing trays and thus production space, heating and air conditioning efforts increased proportionally (Table 4). Energy inputs for illumination, powering of electrical devices and the drying of the pupae are negligible. Nevertheless, to reduce $1 \mathrm{~kg}$ of manure DM the HFfm and HFdm system used 10.2 and $18.3 \mathrm{kWh}$, respectively (Table 3 ).

The input labour, as a possible reference for socio-economic performance, was also found to be substantially different between the HFfm and HFdm model (Figure 4). The manual separation processes that followed the MD and PP units, as well as the EP unit account for considerable labour efforts. The higher manure throughput of the HFdm system caused a higher number of rearing trays to be harvested and which eventually took up more working hours (Table 4 and Figure 4). To reduce $1 \mathrm{~kg}$ of manure DM, the $\mathrm{HFfm}$ system required $1.0 \mathrm{~h}$ and the HFdm system $2.4 \mathrm{~h}$ (Figure 4A and Table 3 ).

The contribution of inputs, specific to the individual unit processes, is illustrated in Figure 5. Measured against kg manure DM reduction, 33\% of the energy inputs and 37\% of the labour inputs in the HFfm system are implied by unit processes that form the internal production loop (31.3\% of $\left.\mathrm{EP}+\mathrm{PP}+\mathrm{S} \_\mathrm{PP}\right)$. In the HFdm system $30 \%$ of the energy inputs and $26 \%$ of the labour inputs are ascribed to the unit processes needed to maintain the adult colony. These differences are explained by higher energy and labour inputs per $\mathrm{kg}$ manure DM reduction in the HFdm system, which necessarily reduce the relative contribution of the unit processes that coincide in both systems $(31.3 \%$ of EP + PP + S_PP) (Figure 5).

Drawing on experiences in rearing trials, we calculated that the manual separation processes (S_PP and S_MD) require $5 \mathrm{~min}$ per batch, which eventually demanded $45 \%(0.46 \mathrm{~h} / \mathrm{kg}$ manure DM reduction) of the disposable working hours in the $\mathrm{HFfm}$ system and $56 \%$ (1.33 h/kg manure DM reduction) in the HFdm system. Further considerable working hours were consumed in the EP (Figure 5). Monitoring of the adult colony, egg collection and feeding measures have been identified as most labour intensive operational steps within this unit process. The PP and MD units require less labour input. Working hours spent provide for preparation of rearing batches (weighing and proportioning of manure, manure inoculation). The finishing unit, comprising the labour input for the drying measures and the packaging of the dried insect product and residue substrates, does not cause a substantial contribution to the overall labour input (Figure 5).

The energy input, largely explained by electricitypowered heating and air conditioning devices, is subject to 
Table 5. Relevant biophysical inputs and outputs calculated per kg manure DM input. Comparison between the manure treatment models with houseflies reared on fresh pig manure (HFfm) and on dewatered pig manure (HFdm). Production models are optimised within the limits of a daily fly egg production of $0.129 \mathrm{~kg}$.

\begin{tabular}{|c|c|c|c|c|}
\hline \multirow[t]{2}{*}{ Input/output } & \multirow[t]{2}{*}{ Unit } & \multicolumn{2}{|l|}{ Amount } & \multirow[t]{2}{*}{ Data sources (foreground data | background data) } \\
\hline & & HFfm & HFdm & \\
\hline Water & 1 & 5.74 & 4.15 & Modelled \\
\hline Production flow & I & 0.48 & 0.41 & $\begin{array}{l}\text { Čičková et al., 2012b; Pastor et al., personal communication | } \\
\text { Ecoinvent } 3.0\end{array}$ \\
\hline Cleaning & I & 5.26 & 3.74 & $\begin{array}{l}\text { Čičková et al., 2012b; Pastor et al., personal communication | } \\
\text { Ecoinvent } 3.0\end{array}$ \\
\hline Space & $m^{2}$ & 0.00073 & 0.00054 & Modelled \\
\hline Production facility ${ }^{1}$ & $m^{2}$ & 0.00071 & 0.00053 & $\begin{array}{l}\text { Čičková et al., 2012b; Pastor et al., personal communication | } \\
\text { Ecoinvent } 3.0\end{array}$ \\
\hline Storage container ${ }^{2}$ & $\mathrm{~m}^{2}$ & 0.00002 & 0.00001 & Assumption 6 | Rubag, 2014; Ecoinvent 3.0 \\
\hline Energy & $\mathrm{kWh}$ & 3.65 & 2.49 & Modelled \\
\hline Heating & kWh & 2.29 & 1.60 & $\begin{array}{l}\text { Čičková et al., 2012b; Pastor et al., personal communication | } \\
\text { Ecoinvent } 3.0\end{array}$ \\
\hline Illumination & kWh & 0.39 & 0.29 & $\begin{array}{l}\text { Čičková et al., 2012b; Pastor et al., personal communication | Döhler, } \\
\text { 2009; Ecoinvent } 3.0\end{array}$ \\
\hline Air conditioning & kWh & 0.61 & 0.37 & $\begin{array}{l}\text { Čičková et al., 2012b; Pastor et al., personal communication | Döhler, } \\
\text { 2009; Ecoinvent } 3.0\end{array}$ \\
\hline Drying chamber & $\mathrm{kWh}$ & 0.23 & 0.14 & $\begin{array}{l}\text { Čičková et al., 2012b; Pastor et al., personal communication | CR, } \\
\text { 2014; Ecoinvent } 3.0\end{array}$ \\
\hline Miscellaneous & kWh & 0.13 & 0.08 & $\begin{array}{l}\text { Čičková et al., 2012b; Pastor et al., personal communication | Airwell, } \\
\text { 2014; Ecoinvent } 3.0\end{array}$ \\
\hline Transportation & tkm & 0.0104 & 0.0067 & Modelled \\
\hline Road, LCV $^{3}<3.5$ tons & tkm & 0.0091 & 0.0057 & Assumption ${ }^{6} \mid$ Ecoinvent 3.0 \\
\hline Tractor and trailer & tkm & 0.0013 & 0.0011 & Assumption ${ }^{6}$ | Ecoinvent 3.0 \\
\hline Labour & $\mathrm{h}$ & 0.36 & 0.32 & Assumption 6 \\
\hline Manure $\left(17.1 \% \mathrm{DM}^{4}\right)$ & $\mathrm{kg}$ & 5.84 & 1.65 & $\begin{array}{l}\text { Modelled | Čičková et al., 2012b; Pastor et al., personal } \\
\text { communication }\end{array}$ \\
\hline Pupa production and oviposition & $\mathrm{kg}$ & 2.67 & 1.65 & $\begin{array}{l}\text { Čičková et al., 2012b; Pastor et al., personal communication | } \\
\text { Reckmann et al., 2013; Ecoinvent } 3.0\end{array}$ \\
\hline Manure degradation & $\mathrm{kg}$ & 3.17 & - & $\begin{array}{l}\text { Čičková et al., 2012b; Pastor et al., personal communication | } \\
\text { Reckmann et al., 2013; Ecoinvent } 3.0\end{array}$ \\
\hline Manure $(23.7 \%$ DM) & $\mathrm{kg}$ & - & 3.03 & $\begin{array}{l}\text { Čičková et al., 2012b; Pastor et al., personal communication | } \\
\text { Reckmann et al., 2013, Ecoinvent } 3.0\end{array}$ \\
\hline Fly eggs & $\mathrm{kg}$ & 0.0038 & 0.0023 & Čičková et al., 2012b; Pastor et al., personal communication | \\
\hline Refined sugar & $\mathrm{kg}$ & 0.1056 & 0.0652 & $\begin{array}{l}\text { Čičková et al., 2012b; Pastor et al., personal communication | } \\
\text { Ecoinvent } 3.0\end{array}$ \\
\hline Milk powder & $\mathrm{kg}$ & 0.1056 & 0.0652 & $\begin{array}{l}\text { Čičková et al., 2012b; Pastor et al., personal communication | } \\
\text { Ecoinvent } 3.0\end{array}$ \\
\hline \multicolumn{5}{|l|}{ Daily consumables } \\
\hline General-purpose cleaner & $\mathrm{ml}$ & 1.211 & 0.652 & Assumption 6 | Davis et al., 1992; Ecoinvent 3.0 \\
\hline Disposable nitrile gloves & $g$ & 4.390 & 2.839 & Assumption 6 | Ecoinvent 3.0 \\
\hline Sponges & g & 0.801 & 0.558 & Assumption ${ }^{6} \mid$ Ecoinvent 3.0 \\
\hline $\mathrm{FIBC}^{5}$ & $\mathrm{p}$ & 0.003 & 0.004 & Assumption ${ }^{6}$ | Texene, 2014; Ecoinvent 3.0 \\
\hline Small PE backs & $p$ & 0.006 & 0.002 & Assumption ${ }^{6}$ | Texene, 2014; Ecoinvent 3.0 \\
\hline Manure reduction (DM) (output, FU4) & $\mathrm{kg}$ & 0.36 & 0.14 & $\begin{array}{l}\text { Modelled | Čičková et al., 2012b; Pastor et al., personal } \\
\text { communication }\end{array}$ \\
\hline$\sum$ manure input (DM) (output, service) & $\mathrm{kg}$ & 1 & 1 & $\begin{array}{l}\text { Modelled | Čičková et al., 2012b; Pastor et al., personal } \\
\text { communication }\end{array}$ \\
\hline
\end{tabular}


Table 5. Continued.

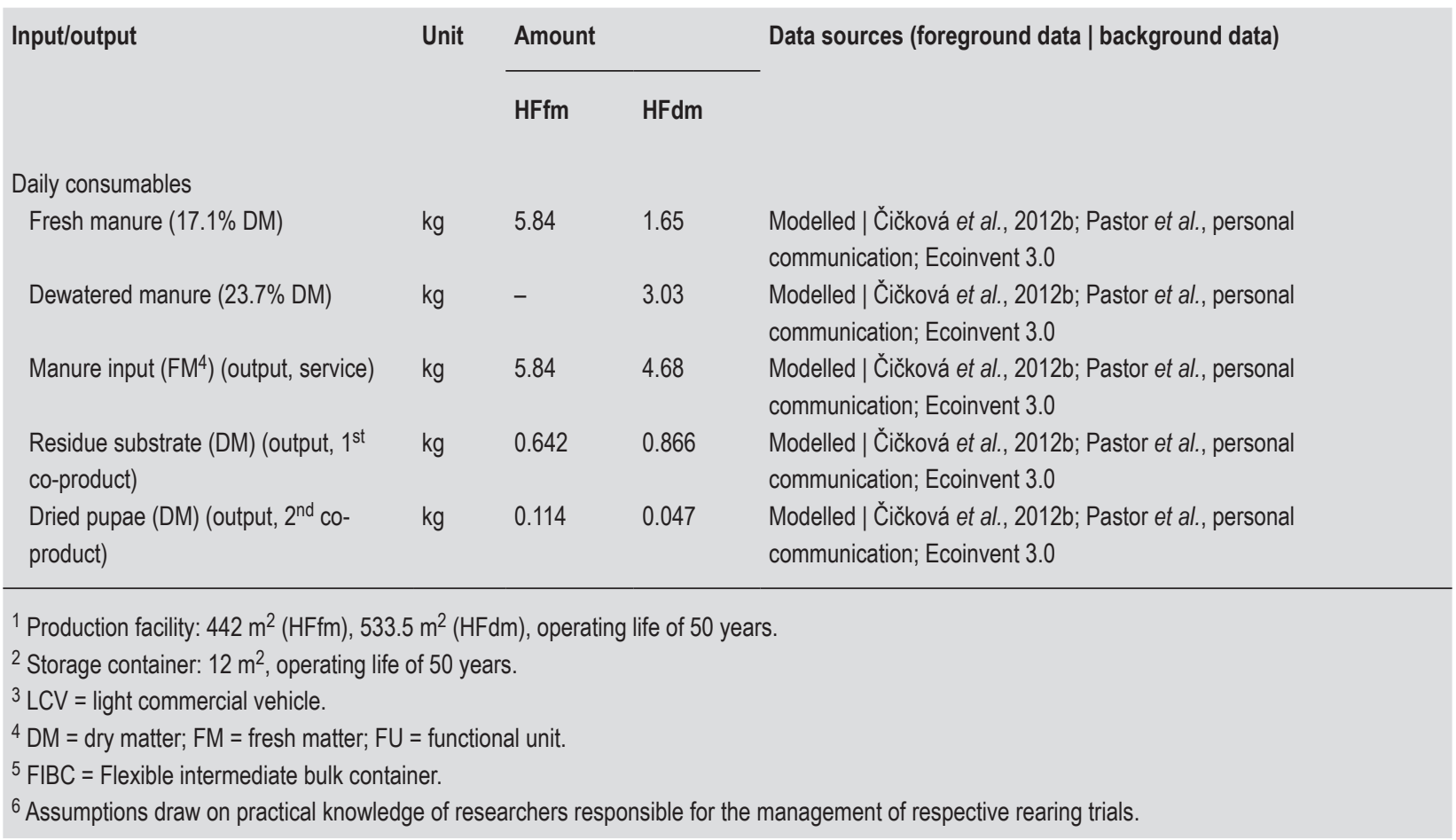

temperature requirements of the different unit processes. In the HFfm system, measured against manure DM reduction, the energy demand of the EP unit accounts for 51\% (5.17 $\mathrm{kWh}$ ) of the overall energy input. The EP unit in the HFdm system contributes with $46 \%$ ( $8.43 \mathrm{kWh})$. Given that a stable and yielding egg production prerequisites well defined and constant climatic conditions, the prominent contribution of the EP unit becomes more comprehensible. Facilitating optimal, year-round temperatures places great demands on heating and air-conditioning systems, which is mirrored in an increased electrical consumption. The energy input in the manure degradation and pupa production unit is comparably lower, as the biological degradation processes in the substrates act as a natural heat-source during the cold month of the year. The separation and finishing units, neither claiming substantial space nor defined temperatures, require comparably low energy inputs. In the HFfm system, for example, the sum of energy inputs in the S_PP, S_MD

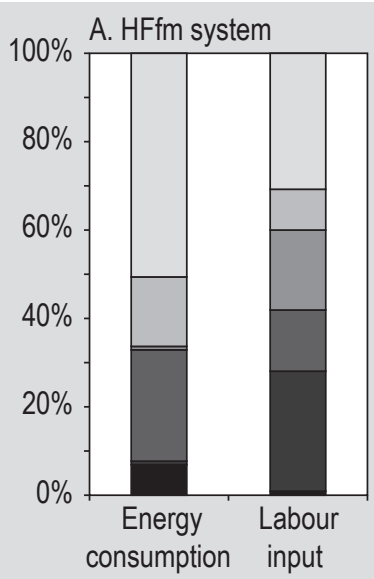

B. HFdm system

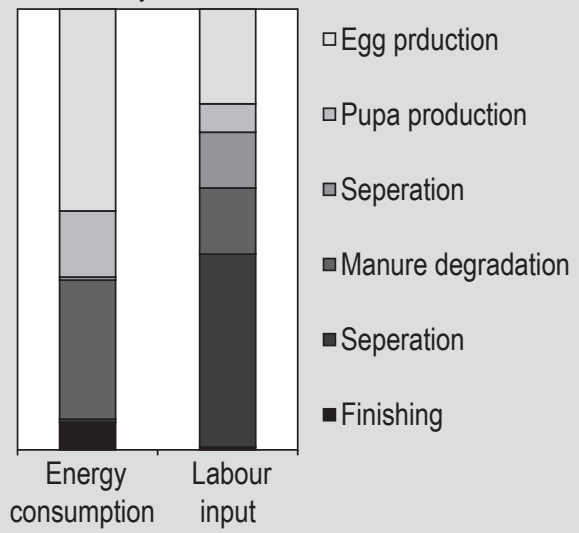

Figure 5. Relative labour and energy inputs of different unit processes per kg manure dry matter reduction. Contrasting the contribution of unit processes between the systems with $(A)$ houseflies reared on fresh pig manure $(\mathrm{HFfm})$ and $(B)$ on dewatered pig manure (HFdm). 
Table 6. Estimated environmental impacts of the systems with houseflies reared on fresh pig manure (HFfm) and on dewatered pig manure (HFdm) per kg manure dry matter reduction. Results of the life cycle impact assessments are reported with reference to agricultural land occupation $\left(\mathrm{m}^{2} \mathrm{yr}\right)$, water depletion potential $\left(\mathrm{m}^{3}\right)$ and fossil depletion potential $\left(\mathrm{kg}_{\text {oil eq }}\right)$ (Čičková et al., 2012a; Pastor et al., 2014).

\begin{tabular}{|c|c|c|c|c|}
\hline \multirow{2}{*}{$\begin{array}{l}\text { Impact category/unit process } \\
\text { contribution }\end{array}$} & \multirow[t]{2}{*}{ Unit } & \multicolumn{2}{|c|}{ Amount } & \multirow[t]{2}{*}{ Data sources (foreground data | background data) } \\
\hline & & HFfm & HFdm & \\
\hline$\sum$ agricultural land occupation & $m^{2} y r$ & 1.395 & 2.661 & Modelled (Čičková et al., 2012b; Pastor et al., personal communication) | Ecoinvent 3.0 \\
\hline Maintenance of adult colonies ${ }^{1}$ & $m^{2} y r$ & 0.500 & 0.815 & Modelled (Čičková et al., 2012b; Pastor et al., personal communication) | Ecoinvent 3.0 \\
\hline Manure degradation ${ }^{2}$ & $m^{2} y r$ & 0.895 & 1.846 & Modelled (Čičková et al., 2012b; Pastor et al., personal communication) | Ecoinvent 3.0 \\
\hline$\sum$ water depletion potential & $\mathrm{m}^{3}$ & 36.399 & 65.592 & Modelled (Čičková et al., 2012b; Pastor et al., personal communication) | Ecoinvent 3.0 \\
\hline Maintenance of adult colonies & $\mathrm{m}^{3}$ & 11.740 & 19.547 & Modelled (Čičková et al., 2012b; Pastor et al., personal communication) | Ecoinvent 3.0 \\
\hline Manure degradation & $\mathrm{m}^{3}$ & 24.659 & 46.045 & Modelled (Čičková et al., 2012b; Pastor et al., personal communication) | Ecoinvent 3.0 \\
\hline$\sum$ fossil depletion potential & $\mathrm{kg}_{\text {oil eq }}$ & 1.913 & 3.441 & Modelled (Čičková et al., 2012b; Pastor et al., personal communication) | Ecoinvent 3.0 \\
\hline Maintenance of adult colonies & $\mathrm{kg}_{\text {oil eq }}$ & 0.625 & 1.039 & Modelled (Čičková et al., 2012b; Pastor et al., personal communication) | Ecoinvent 3.0 \\
\hline Manure degradation & $\mathrm{kg}_{\text {oil eq }}$ & 1.288 & 2.403 & Modelled (Čičková et al., 2012b; Pastor et al., personal communication) | Ecoinvent 3.0 \\
\hline
\end{tabular}

and $\mathrm{F}$ unit account for $8 \%(0.87 \mathrm{kWh})$ of the overall energy inputs, which is almost exclusively attributable to the energy consumption of the drying chamber.

\section{Life cycle impact assessment}

We compared the environmental impact of previous described production systems in terms of agricultural land occupation $\left(\mathrm{m}^{2} \mathrm{yr}\right)$, water depletion potential $\left(\mathrm{m}^{3}\right)$, fossil depletion potential $\left(\mathrm{kg}_{\mathrm{oil} \mathrm{eq}}\right)$.

To reduce $1 \mathrm{~kg}$ manure DM the HFfm system was estimated to occupy $1.40 \mathrm{~m}^{2} \mathrm{yr}$ agricultural land, while the HFdm, with $2.66 \mathrm{~m}^{2} \mathrm{yr}$, was estimated to occupy nearly twice as much area (Table 6).

The impact on water resources is caused by multiple inputs. The cleaning measures are responsible for the largest fraction of water use (92\% HFfm, 90\% HFdm), process specific inputs, such as rewetting of substrate (HFdm) or water provision for drinking (HFfm, HFdm), energy use (through the water requirements of power plants), sealing of land by production facilities and the construction of building infrastructure make up the remainder. Per kg manure DM reduction the HFfm shows a water depletion potential of $36.4 \mathrm{~m}^{3}$ and the HFdm system results in a water depletion potential of $65.6 \mathrm{~m}^{3}$ (Table 6 and Figure 6).

The estimated fossil depletion potential in both systems is to a greater extent attributable to the electrical energy usage. Although transportation and the production and use of various production equipment are as well associated with fossil fuel depletion, their contribution to the overall results turned out minor. Since more than $46 \%$ of Spain's power consumption originates from fossil fuels, the electricity demand in both systems is mirrored in considerable fossil depletion potential $\left(\mathrm{kg}_{\text {oil eq }}\right)(\mathrm{EC}, 2013)$. The fossil depletion potential of reducing $1 \mathrm{~kg}$ manure DM was estimated to be $1.91 \mathrm{~kg}_{\text {oil eq }}$ in the HFfm system and $3.44 \mathrm{~kg}_{\text {oil eq }}$ in the HFdm system (Table 6 and Figure 6). As explained in previous sections, additional space requirements in the HFdm system place higher demands on heating and air-conditioning systems which in turn translates into higher electrical consumption and thus fossil fuel depletion potential.

As it is apparent in Figure 6, the LCIA results accord with the observations done in the LCI analysis (section 'Life cycle inventory analysis'). When impacts are measured against kg manure DM reduction, the HFfm shows comparable lower impacts in all three impact categories. As a matter of fact, the magnitude of differences between the HFfm and HFdm system resemble the differences between input efficiencies that have been observed in section 'Life cycle inventory analysis' (Figure 6).

\section{Sensitivity analysis}

To test how modelled stationary equipment, daily consumables and construction of production facilities, i.e. technological inputs, affect the overall environmental 

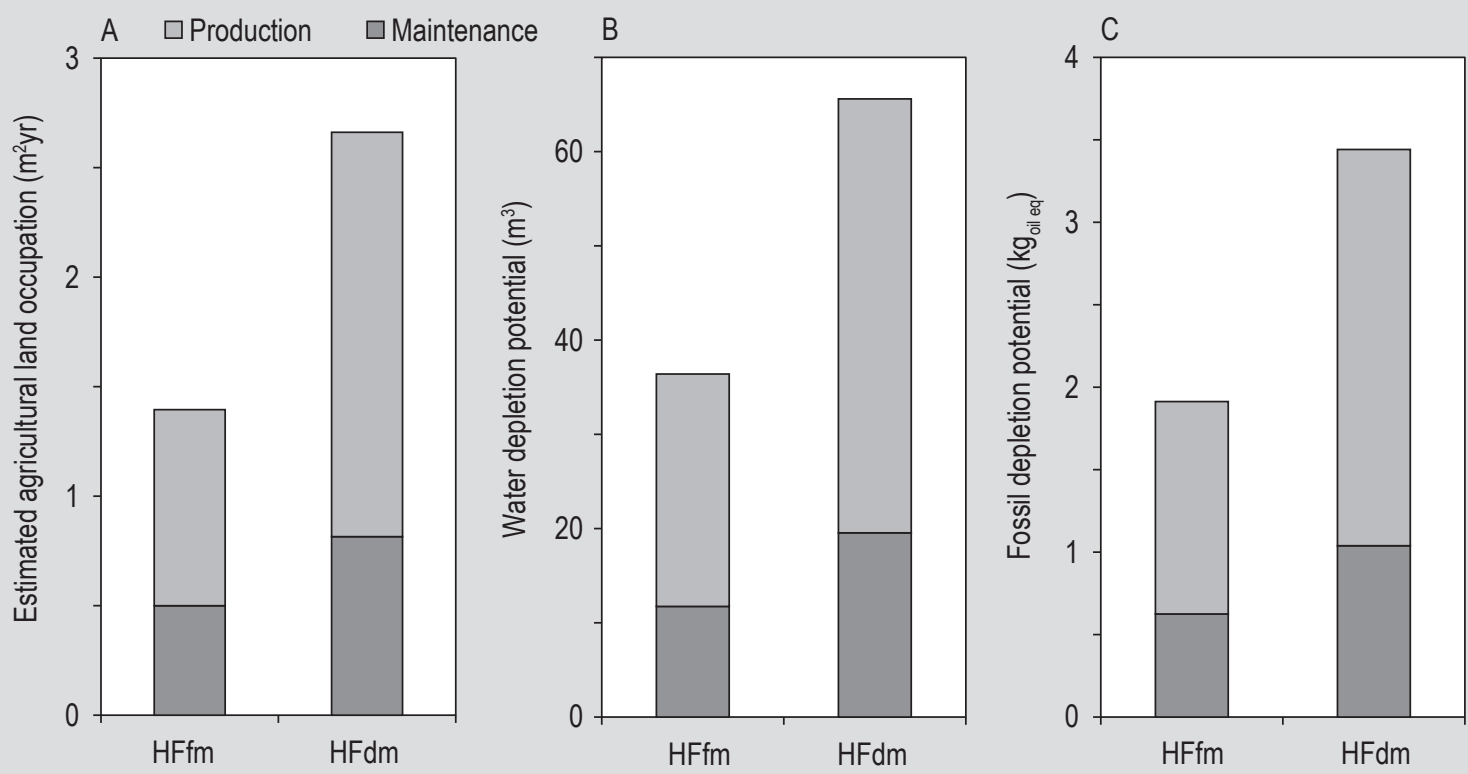

Figure 6. Estimated environmental impacts of the systems with houseflies reared on fresh pig manure (HFfm) and on dewatered pig manure (HFdm) per $\mathrm{kg}$ manure dry matter reduction: (A) estimated agricultural land occupation ( $\left.\mathrm{m}^{2} \mathrm{yr}\right)$, (B) water depletion potential $\left(\mathrm{m}^{3}\right)$, and $(\mathrm{C})$ fossil depletion potential $\left(\mathrm{kg}_{\text {oil eq }}\right)$.

impact of the production models, we deleted all assumed technological inputs and reran the LCIA. Both scenarios showed similar results. For reasons of clarity we will explain the results on the example of the HFfm system.

The modelled technological inputs contributed $1 \%$ to the impact measured in agricultural land occupation, $17 \%$ to the fossil depletion potential and $21 \%$ to the water depletion potential. This relation is exemplified for the HFfm system in Figure 7. This indicates that the environmental impacts of the production models are largely explained by fundamental biophysical inputs, such as energy, water, milk powder and sugar (fly feed) and claimed production space (Figure 7 and Table 3).

\section{Discussion}

The LCI clarified that the input efficiencies of the two systems are variable and subject to the point of reference (manure DM reduction vs manure DM input), whereas the point of reference will depend on the yet hypothetical utility potential of the system's co-product outputs. When evaluated solely by manure DM reduction potential, the HFfm system shows a more favourable input/output ratio. Assuming that the residue substrate has biochemical properties qualifying it as a valuable organic fertiliser, the function of manure treatment would be measured in manure DM input rather than manure DM reduction. In this case, the HFdm system would have a better efficiency.

By adding the expected utility value of the insect product to this equation, the evaluation of the system performances become reversed once again. The nutritional performance and digestibility of insect-derived feedstuff, however, has not yet been examined in feeding trials, and regulatory restrictions, and quality and safety concerns currently do not allow an application for all livestock. Still, recent studies anticipate an application potential as an alternate protein source in feeding regimes of monogastric livestock and aquaculture species (Barroso et al., 2014; Rumpold and Schlüter, 2013; Sánchez-Muros et al., 2014; Van Huis et al., 2014). In function of future market prices, advantage would be given to the HFfm system as it is capable of extracting more than twice as much insect DM from the same input of manure DM. However, the application potential of the two manure treatment models cannot exclusively be ranked by their different performances. The different biophysical properties of the manure types need to be taken into consideration as well. To facilitate a consistent and optimal production, insect-based manure treatment systems require a daily supply of homogeneous substrates. As an excess occurrence of $M$. domestica in stables has proven to reduce the pig fattening performance, it would be further necessary to ensure that manure producing pig operations do not apply prophylactic insecticides to counter the propagation of houseflies in their production facilities (Förster et al., 2009).

Both manure types show residual water contents that limit a cost effective transportation. Although the nutrient concentration and thus transportability of the dewatered pig manure is improved ( $76.3 \%$ water content), a close proximity to industrial-scaled pig producing operations would be an absolute prerequisite for both systems. However, to 


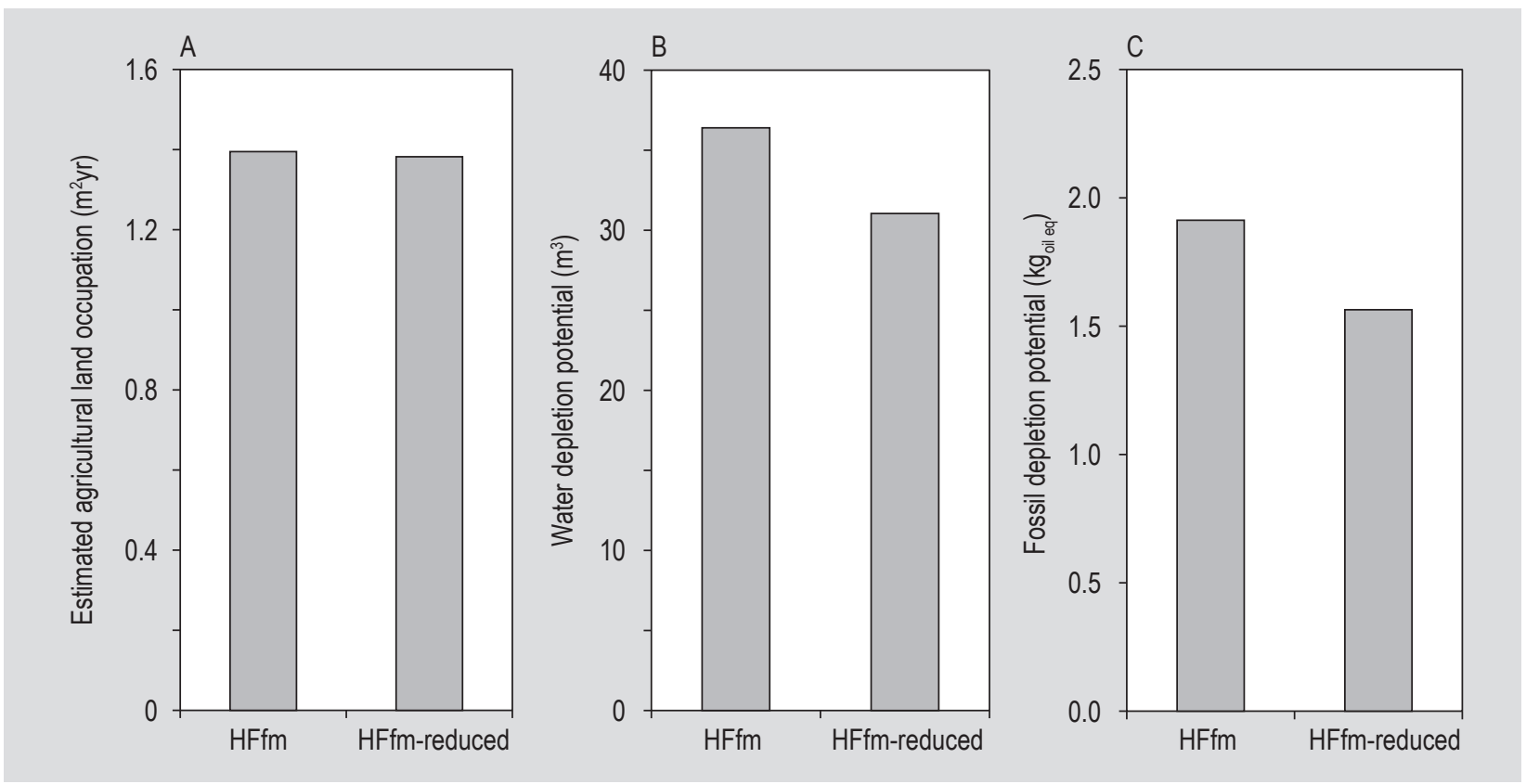

Figure 7. Sensitivity analysis conducted for the housefly reared on fresh pig manure ( $\mathrm{HFfm})$ system. Comparison of the environmental impacts of the original HFfm system with the estimated environmental impact of the HFfm system reduced by the environmental impacts associated to assumed stationary equipment, daily consumables and construction of production facilities, i.e. technological inputs (HFfm-reduced): (A) estimated agricultural land occupation $\left(\mathrm{m}^{2} \mathrm{yr}\right)$, (B) water depletion potential $\left(\mathrm{m}^{3}\right)$ and $(C)$ fossil depletion potential ( $\left.\mathrm{kg}_{\text {oil eq }}\right)$.

conclude on the site suitability, particular attention should be also given to the residue substrates and their proposed application. With residual water contents of 40.9 and $50.38 \%$ for HFfm and HFdm, respectively, it would require an immediate further processing in order to be commercialised and to avoid any putrefaction processes (Real Decreto 506/2013; Agencia Estatal Boletín Oficial del Estado, 2013). As quantity and frequency of fertiliser applications are specific to different cropping system and as fertilisation measures are planned with respect to the development stage and the prevalent weather conditions, facilitating a year-round and immediate further processing in nearby cropping systems appears rather difficult to realise. To provide a tradable alternative towards conventional organic fertilisers, further drying below a water content of $40 \%$, or a customary open-air storage in heaps should be taken into consideration. How an implementation of suggested preservation and/or storage measures would affect the environmental and economic performance of the insectbased manure treatment systems can only be clarified in further LCA studies of broader scope.

Although subject to the point of reference, our results provide initial information and comparative values on processes efficiencies of different manure types in insectbased manure treatment systems. The presented results, however, are insufficiently comprehensive to conclude on the ranking of the tested manure types, with reference to process efficiency and environmental sustainability. Due to data limitations, the environmental costs of the dewatering process, located upstream to the HFdm system, has not yet been taken into account. If current system boundaries would be extended towards further upstream process steps, the environmental impact of a preceding dewatering step would be partially burdened to the account of the HFdm system, which is likely to deteriorate the environmental performance of the HFdm system (Nolan et al., 2012).

The LCI analysis provides a comprehensive insight on the inputs necessary to reduce $1 \mathrm{~kg}$ manure DM. Especially the inputs of water, energy and labour received attention. The reduction of $1 \mathrm{~kg}$ manure DM is offset by a water consumption of $16 \mathrm{l}$ (HFfm) and $31 \mathrm{l}$ (HFdm). In the light that the analysed treatment models have been designed to facilitate manure reduction, the extent of water inputs raises questions. The LCI revealed that $92 \%$ (HFfm), respectively $90 \%$ (HFdm) of the water inputs are explained by cleaning efforts. As anaerobic conditions are reported to limit the biodegradation by housefly larvae, the manure in both models was foreseen to be evenly spread in plastic trays keeping the filling height below $7 \mathrm{~cm}$ (Čičková et al., 2012b). To keep the space demand in reasonable scope, we assumed the plastic trays to be stacked in trolleys. This itemisation in the PP and MD unit implied high cleaning efforts and thus water inputs in order to maintain an adequate level of hygiene. To reduce the cleaning-related water use it would be necessary to search for alternate cleaning measures or rearing vessels that show a more favourable volume/ surface ratio. 
The highly fragmented practical/spatial organisation of the process is also mirrored in the estimated labour inputs. Repetitive labour efforts for cleaning and preparatory measures cumulate with an increasing fragmentation of the process organisation. However, with $45.2 \%$ (HFfm) and $56.4 \%$ (HFdm) of the disposable working hours, the manual separation steps are responsible for most of the required working hours. This indicates a particular improvement potential. Designing an automated separation device appears promising to lower the required labour inputs considerably.

The production-related energy usage was found to be essentially linked with required heating efforts. To reduce $1 \mathrm{~kg}$ of manure DM the production models required 10.2 kWh (HFfm) and 18.3 kWh (HFdm). Applying end-user energy prices from Spain (2013: € 0.19/kWh) implies costs of $€ 1.62$ (HFfm) and $€ 2.96$ (HFdm) per kg manure DM reduction (EEP, 2013). To lower these costs, more efficient heating devices would be required. Electricity is not necessarily the best energy carrier for heating. Although subject to the electricity mix within a geographical context of question, e.g. a natural-gas heating system could provide a less environmental burdensome alternative. It is further important to apply adequate insulation of the production facilities. To save heating efforts in general, application in climates that facilitate year-round optimal temperatures should be promoted.

In order to analyse the improvement potential of the production systems, we took a closer look at the contribution of inputs throughout the different unit processes. It became apparent that unit processes that purpose maintenance of the adult colonies considerably contribute to the overall inputs. In the HFfm system 33\% of the energy inputs (HFdm: $30 \%$ ) and $37 \%$ of the labour inputs (HFdm: $26 \%$ ) originate from unit processes that form the internal production loop. As the egg production is the limiting factor in manure treatment with houseflies, it is important to maintain the adult colonies in optimal conditions. In other words, maximising the egg output requires increased resource and management efforts. This principle inspired the assumption that the egg producing adult colonies are kept in small units (80 cages), instead of keeping them in one coherent unit. Although the segmentation of the EP unit coincides with an increased material and resource input, managing smaller units allows for a more precise process control and provides opportunity to mitigate possible production failures. Due to lack of data we could not evaluate to which extent the segmented process organisation and observed input/ output ratio corresponds to an optimal specific production intensity. We expect a further aggregation of rearing units to be accompanied by economy of scale effects, likely to be mirrored in lesser labour and resource inputs. However, regardless the recommended optimisation measures, it is clear that the egg production needs a significant improvement. In fact, experimental trials conducted in production systems developed in Slovakia showed a higher egg production than the one established in Spain (Čičková et al., 2012b). Since the adult cages were different, we further consider that the cage design plays an important role in the egg production obtained, and adding some modifications to the current design, the egg production could be improved. The adult density in the cages could also be decreased, as the Slovak facility cages only contained 25,000 pupae and the egg production was four times higher. Thus, the quantity of pupae needed for the egg production unit would be lower. Another consideration that could improve the model is to eliminate the pupa production (PP) unit, thus, the pupae for the adult colony could be obtained directly from the manure degradation unit. These pupae would be smaller, but it has been reported by Pastor et al. (2011) that the size of housefly pupae does not affect the number of eggs produced.

As expected, the LCA results followed the patterns observed in the LCI analysis. When impacts are measured against $\mathrm{kg}$ manure DM reduction, the HFfm shows lower impacts than the HFdm for all three impact categories. The sensitivity analysis further revealed that the fundamental biophysical inputs, directly associated with the insect-steered manure treatment (space, water, energy, milk powder and sugar), are responsible for $99 \%$ of the occupied agricultural land, 83\% of the fossil depletion potential and $79 \%$ of the estimated water depletion potential. This result shows firstly that the assumed technological inputs and the intrinsic uncertainties related to them do not influence the estimated results to a greater extent. Secondly, the results define input parameters with high improvement potential. In particular, fossil fuel and water depletion could be reduced if suitable solutions were developed to reduce energy usage (heating) and water consumption (cleaning).

Although this assessment selectively made on agricultural land occupation, water and fossil depletion potential has proven suitable to detect prevailing process inefficiencies in the current production concepts, it does not inform sufficiently inclusive on the overall environmental ramifications. To conduct a comprehensive environmental impact assessment, including the most common LCA categories such as global warming potential, it would require foreground inventory data on process-related emissions. Though recent studies on greenhouse gas emission from conventional swine manure treatment plants (Prapaspongsa et al., 2010; Riaño and García-González, 2015) and specific insect production systems (Oonincx and De Boer, 2012; Oonincx et al., 2010) provide initial indications on the possible nature and magnitude of such emissions, the biophysical context and metabolic processes on which emissions have been monitored did not accord with the experimental trials that our models are building on. Employing these reported emission factors in the 
current study was therefore considered incoherent and non-representative. In order to close this knowledge gap and thus provide a comprehensive picture on the environmental performance of this novel manure treatment concept, further examinations of process-related emissions of $M$. domestica reared on pig manure will be required.

\section{Conclusions}

The investigated system designs only represent an extract of possible production scenarios. The results discussed in previous sections are highly site specific and do not allow to draw general conclusions about fly rearing systems. However, the analysed input and output relations and environmental impacts shall serve as a point of reference for future research and development activities.

The LCA results followed the patterns observed in the LCI analysis. The analysed input efficiency of water and energy directly translates into a fossil depletion potential of 1.9 $\mathrm{kg}_{\text {oil eq }}(\mathrm{HFfm})$, respectively $3.4 \mathrm{~kg}_{\text {oil eq }}(\mathrm{HFdm})$ attributed to the reduction of $1 \mathrm{~kg}$ manure DM. The water depletion potential was estimated $36.4 \mathrm{~m}^{3}$ (HFfm) and $65.6 \mathrm{~m}^{3}$ (HFdm). Regarding the space requirements, per kg manure DM reduction the modelled manure treatment systems were estimated to occupy $1.4 \mathrm{~m}^{2} \mathrm{yr}(\mathrm{HFfm})$ and $2.7 \mathrm{~m}^{2} \mathrm{yr}$ (HFdm) agricultural land. Although not related to focal impact categories, the LCI analysis yielded information on required labour inputs. To reduce $1 \mathrm{~kg}$ of manure DM and simultaneously process respective amounts of dried insect product and residue substrates the HFfm system required 1.0 working hours and the HFdm system $2.36 \mathrm{~h}$.

The LCI analysis further highlighted that the input efficiency of the two systems is variable and subject to the point of reference. When measured against manure DM reduction, the HFfm system performed in a more favourable input efficiency. However, if the function of manure treatment would be measured in manure DM input, the HFdm system would perform in a more favourable efficiency. To find the appropriate point of reference, it requires further research to validate the yet hypothetical utility potential of the coproducts. In order to finally conclude on the operational and environmental superiority of the assessed production systems, it would be further necessary to broaden the LCA scope to an extent that allows to account the environmental costs of associated upstream process steps, such as the pre-treatment of the manure.

It has been further established that the application potential of these novel manure treatment concepts is subject to sitespecific geographical and socio-economic circumstances. Regions with year-round optimal temperatures and a high density of CAOs, appear most suitable. As analysed manure types show limited transportability, we further recommend an application in close proximity to industrial-scale pig production operations. It is further important to ensure that the manure providing facilities do not apply prophylactic insecticides to counter the propagation of flies in their slurry tanks.

When analysing the contribution of unit processes to the estimated impacts and labour inputs, we identified considerable improvement potential. To lower the fossil depletion potential, we recommend an application of more efficient heating and air-conditioning devices and adequate insulation of the production facilities. We also recommend to design suitable automated separation measures, as manual separation of pupae and residue substrates required substantial labour input. To lower the water use, we challenge future research to conceive and design alternate cleaning measures and/or rearing vessels with more favourable volume/surface ratio. As the fragmentation of the process went along with cumulative cleaning and labour efforts we also advise to aggregate rearing steps and slenderise the technological setup to benefit from economy of scale effects. If expected savings make up for possible reduction in productivity can only be clarified in designated rearing trials.

A sensitivity analysis conducted solely for fundamental biophysical inputs and outputs highlighted that the assumed stationary equipment, daily consumables and construction of production facilities did not substantially influence the presented LCIA results.

\section{Acknowledgements}

The research leading to these results has received funding from the European Union's Seventh Framework Programme for research, technological development and demonstration under grant agreement no. 312084 (PROteINSECT). The authors are thankful to members of the PROteINSECT consortium. We also thank colleagues of the Division Forest, Nature and Landscape at KU Leuven, who provided valuable inputs and recommendations.

\section{Author contributions}

Conceived and designed the manure treatment models: M. Roffeis, B. Pastor, S. Rojo, A. Martinez-Sanchez and Y. Velásquez. Data analysis and LCA: M. Roffeis, W.M.J. Achten, J. Almeida and B. Muys. Wrote the manuscript: M. Roffeis, W.M.J. Achten, J. Almeida and B. Muys.

\section{Supplementary material}

Supplementary material can be found online at http:// dx.doi.org/10.3920/JIFF2014.0021.

Table S1. Schematic illustration of the process organisation and sequences within the egg production unit. 
Table S2. Schematic illustration of the process organisation and sequences within the pupa production unit.

Table S3. Schematic illustration of the process organisation and sequences within the manure degradation unit of the system with housefly reared on fresh pig manure.

Table S4. Schematic illustration of the process organisation and sequences within the manure degradation unit of the system with housefly reared on dewatered pig manure.

\section{References}

Agencia Estatal Boletín Oficial del Estado, 2013. Real Decreto 506/2013, de 28 de junio, sobre productos fertilizantes. Boletín Oficial del Estado 164: 51119-51207.

Airwell, 2014. WAP/WAD RC - product specification. Ecoinvent, Zurich, Switzerland. Available at: http://tinyurl.com/pm27rgr.

Barroso, F.G., Haro, C.D., Sánchez-Muros, M.-J., Venegas, E., MartínezSánchez, A. and Pérez-Bañón, C., 2014. The potential of various insect species for use as food for fish. Aquaculture 422-423: 193-201.

Basbagill, J., Flager, F., Lepech, M. and Fischer, M., 2013. Application of life-cycle assessment to early stage building design for reduced embodied environmental impacts. Building and Environment 60: 81-92.

CarlRoth (CR), 2014. Drying chamber Heratherm, general protocolOGS400-product specification. CR, Karlsruhe, Germany. Available at: http://tinyurl.com/nhbvfgd.

Čičková, H., Kozánek, M., Morávek, I. and Takáč, P., 2012a. A behavioral method for separation of house fly (Diptera: Muscidae) larvae from processed pig manure. Journal of Economic Entomology 105: 62-66.

Čičková, H., Kozánek, M. and Takáč, P., 2013. Improvement of survival of the house fly (Musca domestica L.) larvae under mass-rearing conditions. Bulletin of Entomological Research 103: 119-125.

Čičková, H., Pastor, B., Kozánek, M., Martínez-Sánchez, A.S., Rojo, S. and Takáč, P., 2012b. Biodegradation of pig manure by the housefly, Musca domestica: a viable ecological strategy for pig manure management. PLoS ONE 7: e32798.

Davis, G.A., Dickey, P., Duxbury, D., Griffith, B., Oakley, B. and Cornell, K., 1992. Household cleaners. Environmental evaluation and purposed standards for general purpose household cleaners. University of Tennessee, Center for Clean Products and Clean Technologies, Knoxville, TN, USA.

Dawson, C.J. and Hilton, J., 2011. Fertiliser availability in a resourcelimited world: production and recycling of nitrogen and phosphorus. Food Policy 36: S14-S22.

Döhler, H., 2009. Faustzahlen für die Landwirtschaft, 14. KTBL Kuratorium für Technik und Bauwesen in der Landwirtschaft, Darmstadt, Germany, 1180 pp.

European Commission (EC), 2013. EU energy in figures - statistical pocketbook 2013. Publications Office of the European Union, Luxembourg, Luxembourg. Available at: http://tinyurl.com/ q3gymec.
Europe's Energy Portal (EEP), 2013. Retail (end-user) energy prices for households, May 2013. EU BCN, Etten-Leur, the Netherlands. Available at: http://tinyurl.com/ovk4mk5.

Förster, M., Klimpel, S. and Sievert, K., 2009. The house fly (Musca domestica) as a potential vector of metazoan parasites caught in a pig-pen in Germany. Veterinary Parasitology 160: 163-167.

Freegard, K. and Claes, M., 2009. Compositional analysis of kerbside collected small WEEE, Waste \& Resources Action Programme. WRAP, Axion Recycling Ltd., Banbury, UK.

Godfray, H.C.J., Beddington, J.R., Crute, I.R., Haddad, L., Lawrence, D., Muir, J.F., Pretty, J., Robinson, S., Thomas, S. and Toulmin, C., 2010. Food security: the challenge of feeding 9 billion people. Science 327: 812-818.

Goedkoop, M., Heijungs, R., Huijbregts, M., De Schryver, A., Struijs, J. and Van Zelm, R., 2008. ReCiPe 2008 - a life cycle impact assessment method which comprises harmonised category indicators at the midpoint and the endpoint level. Report I: characterisation. Ministry of Housing, Spatial Planning and Environment (VROM), The Hague, the Netherlands, $126 \mathrm{pp}$.

Guinée, J.B., Heijungs, R. and Huppes, G., 2004. Economic allocation: examples and derived decision tree. The International Journal of Life Cycle Assessment 9: 23-33.

International Organization for Standardization (ISO),2006a. ISO 14040:2006: Environmental management - life cycle assessment - principles and framework. ISO, Geneva, Switzerland.

International Organization for Standardization (ISO),2006b. ISO 14044:2006: Environmental management - life cycle assessment requirements and guidelines. ISO, Geneva, Switzerland.

Lal, R., 2013. Food security in a changing climate. Ecohydrology \& Hydrobiology 13: 8-21.

Lebuf, V., Accoe, F. and Van Elsacker, S., 2013. Techniques for nutrient recovery from digestate - inventory. Report of the ARBOR Interreg IVB project. Vlaams Coördinatiecentrum Mestwerking, Brugge, Belgium, 28 pp.

Lesschen, J.P., Van den Berg, M., Westhoek, H.J., Witzke, H.P. and Oenema, O., 2011. Greenhouse gas emission profiles of European livestock sectors. Animal Feed Science and Technology 166-167: 16-28.

Miller, B.F., Teotia, J.S. and Thatcher, T.O., 1974. Digestion of poultry manure by Musca domestica 1. British Poultry Science 15: 231-234.

Newton, L., Sheppard, C., Watson, D.W., Burtle, G. and Dove, R., 2005. Using the black soldier fly, Hermetia illucens, as a value-added tool for the management of swine manure. Animal and Poultry Waste Management Center, North Carolina State University, Raleigh, NC, USA, 17 pp.

Nijdam, D., Rood, T. and Westhoek, H., 2012. The price of protein: review of land use and carbon footprints from life cycle assessments of animal food products and their substitutes. Food Policy 37: 760-770.

Nolan, T., Troy, S.M., Gilkinson, S., Frost, P., Xie, S., Zhan, X., Harrington, C., Healy, M.G. and Lawlor, P.G., 2012. Economic analyses of pig manure treatment options in Ireland. Bioresource Technology 105: 15-23.

Oonincx, D.G.A.B. and De Boer, I.J.M., 2012. Environmental impact of the production of mealworms as a protein source for humans - a life cycle assessment. PLoS ONE 7: e51145. 
Oonincx, D.G.A.B., Van Itterbeeck, J., Heetkamp, M.J.W., Van den Brand, H., Van Loon, J.J.A. and Van Huis, A., 2010. An exploration on greenhouse gas and mmmonia production by insect species suitable for animal or human consumption. PLoS ONE 5: e14445.

Parry, M.L., Canziani, O., Palutikof, J., Van der Linden, P. and Hanson, C. (eds.), 2007. Climate change 2007: impacts, adaptation and vulnerability. Contribution of the working group II to the fourth assessment report of the Intergovernmental Panel on Climate Change. IPCC, Cambridge University Press, Cambridge, UK.

Pastor, B., Čičková, H., Kozanek, M., Martinez-Sanchez, A.S., Takac, P. and Rojo, S., 2011. Effect of the size of the pupae, adult diet, oviposition substrate and adult population density on egg production in Musca domestica (Diptera: Muscidae). European Journal of Entomology 108: 10.

Pastor, B., Martínez-Sánchez, A.S., Ståhls, G.A. and Rojo, S., 2014. Introducing improvements in the mass rearing of the housefly: biological, morphometric and genetic characterization of laboratory strains. Bulletin of Entomological Research 104: 486-493.

Pawelzik, P., Carus, M., Hotchkiss, J., Narayan, R., Selke, S., Wellisch, M., Weiss, M., Wicke, B. and Patel, M.K., 2013. Critical aspects in the life cycle assessment (LCA) of bio-based materials - reviewing methodologies and deriving recommendations. Resources, Conservation and Recycling 73: 211-228.

Petersen, S.O., Sommer, S.G., Béline, F., Burton, C., Dach, J., Dourmad, J.Y., Leip, A., Misselbrook, T., Nicholson, F., Poulsen, H.D., Provolo, G., Sørensen, P., Vinnerås, B., Weiske, A., Bernal, M.P., Böhm, R., Juhász, C. and Mihelic, R., 2007. Recycling of livestock manure in a whole-farm perspective. Livestock Science 112: 180-191.

Prapaspongsa, T., Christensen, P., Schmidt, J.H. and Thrane, M., 2010. LCA of comprehensive pig manure management incorporating integrated technology systems. Journal of Cleaner Production 18: 1413-1422.

Reckmann, K., Traulsen, I. and Krieter, J., 2013. Life cycle assessment of pork production: a data inventory for the case of Germany. Livestock Science 157: 586-596.

Riaño, B. and García-González, M.C., 2015. Greenhouse gas emissions of an on-farm swine manure treatment plant - comparison with conventional storage in anaerobic tanks. Journal of Cleaner Production 103: 542-548.

Rubag, 2014. Materialcontainer MACON - product specification. Rubag, Birsfelden, Switzerland. Available at: http://tinyurl.com/ ofvmez2.
Rumpold, B.A. and Schlüter, O.K., 2013. Potential and challenges of insects as an innovative source for food and feed production. Innovative Food Science \& Emerging Technologies 17: 1-11.

Sánchez-Muros, M.-J., Barroso, F.G. and Manzano-Agugliaro, F., 2014. Insect meal as renewable source of food for animal feeding: a review. Journal of Cleaner Production 65: 16-27.

Sandars, D.L., Audsley, E., Cañete, C., Cumby, T.R., Scotford, I.M. and Williams, A.G., 2003. Environmental benefits of livestock manure management practices and technology by life cycle assessment. Biosystems Engineering 84: 267-281.

Sheppard, C., 1983. House fly and lesser fly control utilizing the black soldier fly in manure management systems for caged laying hens. Environmental Entomology 12: 1439-1442.

Smet, E., Debruyne, J., Deckx, J. and Deboosere, S., 2003. Manure treatment according to the Trevi concept. Communications in Agricultural and Applied Biological Sciences: 125-131.

Steinfield, H., Gerber, P., Wassenaar, T., Castel, V. and De Haan, C., 2006. Livestock's long shadow: environmental issues and options, 1. FAO, Rome, Italy, 3-176 pp.

Swarr, T.E., Hunkeler, D., Klöpffer, W., Pesonen, H.-L., Ciroth, A., Brent, A.C. and Pagan, R., 2011. Environmental life-cycle costing: a code of practice. The International Journal of Life Cycle Assessment 16: 389-391.

Swiss Federal Laboratories for Materials Science and Technology (EMPA), 2014. e-waste definition. EMPA, Dübendorf, Switzerland. Available at: http://ewasteguide.info/introduction/e-waste.

Texene, 2014. Flexible Intermediate Bulk Container (FIBC) - product specification. Texene LLC, Summerville, SC, USA. Available at: http://tinyurl.com/orwxzcd.

Tilman, D., Cassman, K.G., Matson, P.A., Naylor, R. and Polasky, S., 2002. Agricultural sustainability and intensive production practices. Nature 418: 671-677.

Tscharntke, T., Clough, Y., Wanger, T.C., Jackson, L., Motzke, I., Perfecto, I., Vandermeer, J. and Whitbread, A., 2012. Global food security, biodiversity conservation and the future of agricultural intensification. Biological Conservation 151: 53-59.

Van Huis, A., Van Itterbeeck, J., Klunder, H., Mertens, E., Halloran, A., Muir, G. and Vantomme, P., 2014. Edible insects: future prospects for food and feed security. FAO Forestry Paper. FAO, Rome, Italy, $189 \mathrm{pp}$. 